\title{
Epidemiologie und Prävention von nosokomialen Infektionen in der Pädiatrie
}

\author{
Thomas Hauer, Arne Simon und Markus Dettenkofer
}

1

\section{Definition}

Eine nosokomiale Infektion (griech. „nosokomeíon“, Krankenhaus) ist laut Infektionsschutzgesetz definiert als eine „Infektion mit lokalen oder systemischen Infektionszeichen als Reaktion auf das Vorhandensein von Erregern oder ihrer Toxine, die im zeitlichen Zusammenhang mit einer stationären oder einer ambulanten medizinischen Maßnahme steht, soweit die Infektion nicht bereits vorher bestand“".

Bei länger oder wiederholt hospitalisierten Kindern bestehen häufig Grundkrankheiten, die invasive diagnostische und therapeutische Maßnahmen erfordern. Patientenspezifische Risikofaktoren und die Exposition gegenüber einer Vielzahl potenziell pathogener Mikroorganismen bei evtl. noch unreifem Immunsystem bzw. noch fehlender Immunität bestimmen das Risiko, eine nosokomiale Infektion (NI) zu erwerben. Mit unterschiedlichen Altersgruppen sind unterschiedliche Übertragungswege bzw. klinische Manifestationen von Infektionskrankheiten verbunden.

Aufgrund ihrer altersentsprechenden Verhaltensweisen sind Kleinkinder besonders häufig Erregern ausgesetzt, die sie ihrerseits durch engen Kontakt auf andere übertragen können. Durch den notwendigerweise engen Kontakt mit den Kindern werden die Hände oder die Kleidung von Betreuungspersonen leicht mit Sekreten kontaminiert. Die „Inkontinenz“ der kleinen Kinder erleichtert die Übertragung darmpathogener Erreger oder von Zytomegalieviren, die im Urin ausgeschieden

T. Hauer $(\bowtie)$

Deutsches Beratungszentrum für Hygiene, Freiburg/Breisgau,

Deutschland

E-Mail: hauer@bzh-freiburg.de

A. Simon

Klinik für Pädiatrische Onkologie und Hämatologie,

Universitätsklinikum des Saarlandes, Homburg/Saar, Deutschland

E-Mail: arne.simon@uks.eu

M. Dettenkofer

Institut für Krankenhaushygiene und Infektionsprävention, Gesundheitsverbund Landkreis Konstanz, Radolfzell, Deutschland

E-Mail: markus.dettenkofer@glkn.de werden. Auch virale Erreger von Atemwegsinfektionen werden von Kindern über die akute Erkrankungsphase hinaus in Atemwegssekreten ausgeschieden. Auf dem Boden krabbelnde Kleinkinder können in größerem Maße mit kontaminierten Flächen in Berührung kommen als Erwachsene. Ein besonders hohes Risiko für NI haben intensivmedizinisch behandelte Früh- und Neugeborene, pädiatrische Intensivpatienten, Kinder mit hämodynamisch relevanten angeborenen Herzfehlern, die einer frühen operativen Korrektur bedürfen, Patienten mit chronischen Erkrankungen, wie der zystischen Fibrose sowie immundefiziente oder -supprimierte Patienten, z. B. aus der pädiatrischen Onkologie und Hämatologie. Bei Letzteren können auch fakultativ pathogene Mikroorganismen zu einer opportunistischen Infektion führen.

Außerdem kommt es im Krankenhaus durch die häufig eingesetzte Antibiotikatherapie zu einer Selektion von Erregern mit problematischem Resistenzspektrum, wodurch die Therapie nosokomialer Infektionen erschwert und das Infektionsrisiko durch Übertragungen dieser Erreger erhöht wird. Der ungezielte und nicht leitlinienkonforme Einsatz von Antiinfektiva wird auch in der stationären und ambulanten Pädiatrie in den letzten Jahren kritischer hinterfragt.

Um Infektionen durch Übertragungen von Krankheitserregern über das Personal oder andere Patienten bzw. auch über die patienteneigene Flora zu vermeiden, ist es essenziell, die möglichen und wahrscheinlichen Übertragungswege von Krankheitserregern zu kennen und geeignete Maßnahmen zu treffen, um eine Übertragung zu vermeiden. Besonders zu betonen ist, dass die größte Bedeutung zur Infektionsprävention im Krankenhaus die Händehygiene hat.

\section{2 Übertragungswege}

Man unterscheidet bei der Übertragung von Krankheitserregern den direkten vom indirekten Übertragungsweg. Dabei kommt die direkte Übertragung seltener vor: 
- Die direkte Übertragung geschieht z. B. durch direkten Kontakt oder über respiratorische Tröpfchen (Distanzen $<2 \mathrm{~m}$ ). Seltener ist die aerogene Übertragung durch die Luft über Partikel, die kleiner als $5 \mu \mathrm{m}$ sind und daher bis in die tiefen Atemwege vordringen können, wie z. B. bei der offenen Lungentuberkulose (ausschließlich aerogen), bei Varizellen und bei Masern (zusätzlich zur Kontakt- und Tröpfchenübertragung), sowie im Zusammenhang mit bestimmten invasiven Prozeduren (z. B. Bronchoskopie).

- Die indirekte Übertragung findet in erster Linie über die kontaminierten Hände des Personals oder weiterer Kontaktpersonen statt. Indirekt können Infektionen jedoch auch über kontaminierte Oberflächen, Medizinprodukte, Wasser, Blut und Blutprodukte, Lebensmittel oder tierische Vektoren (z. B. Insekten) übertragen werden.

Von einer vertikalen Übertragung spricht man bei der prä-, peri- oder postnatalen Übertragung von Krankheitserregern von der Mutter auf das Kind (z. B. bei Toxoplasmose, Syphilis, Hepatitis B, HIV, CMV, VZV oder Rötelnvirus).

\section{1 Übertragung von Patient zu Patient}

Hier sind die Basishygienemaßnahmen entscheidend. Schon durch die strikte Einhaltung der grundsätzlich bei allen Patienten anzuwendenden Basishygienemaßnahmen lassen sich nicht nur Übertragungen von mit Blut oder Körperflüssigkeiten assoziierten Infektionen, sondern auch Kontakt- und die meisten Tröpfcheninfektionen verhüten.

\subsection{Spezielle Situationen}

In besonderen Situationen sind weitergehende Hygienemaßnahmen einzuhalten, denn bei bestimmten Patientengruppen sind auch ohne gravierende Fehler in der Basishygiene Infektionsübertragungen möglich: So sind bei pädiatrischonkologischen Patienten Hepatitis-B-Virus-Übertragungen (HBV) durch Schleimhautkontakt mit Gegenständen beschrieben, die mit dem Speichel infizierter Kinder kontaminiert waren. HBV-Infektionen unter zytostatischer Chemotherapie führen in einem sehr hohen Prozentsatz zu einer persistierenden Virämie mit extrem hohen Viruskonzentrationen, ohne dass die Kinder klinisch und laborchemisch eine Hepatitis ausbilden. Unter Chemotherapie treten vielfach Schleimhautschädigungen mit Mikroblutungen auf. Kleine Kinder nehmen ihr Spielzeug immer in den Mund. Dadurch entsteht für nichtinfizierte Kontaktkinder auf der Station ein erhöhtes Infektionsrisiko. Ebenso können bei Nachweis von Infektionserregern mit besonderem epidemischem Potenzial, z. B. Methicillin-resistenten Staphylocco- cus aureus, Vancomycin-resistenten Enterokokken oder bestimmten gramnegativen Erregern mit speziellen Multiresistenzen (MRGN) weitergehende Screening- und Isolierungsmaßnahmen notwendig werden. Für Patienten, Eltern und Personal belastende Hygienemaßnahmen müssen dabei immer rational über plausible Infektionswege begründbar sein und in einem klinikinternen Standard festgelegt werden.

Naturgemäß besteht in Wartezonen der Kinderklinik oder von Spezialambulanzen ein besonderes Infektionsrisiko, vor allem zu Zeiten epidemisch auftretender viraler Atemwegsinfektionen. Dies sollte soweit möglich durch ein sofortiges Screening aller Patienten auf respiratorische Symptome und Exantheme und deren räumliche Trennung von den anderen Wartenden verringert werden.

\section{3 Übertragung von Personal auf Patienten}

Varizellen, Masern, virale Atemwegsinfektionen (z. B. Influenza), Pertussis, infektiöse Durchfallerkrankungen (z. B. Noro- oder Rotaviren) und ähnliche Erkrankungen können durch Personal von extern oder innerhalb des Krankenhauses erworben und direkt oder indirekt auf die Patienten übertragen werden. Besonders Frühgeborene und immunsupprimierte Kinder sind gefährdet. Ein Risiko besteht auch bei chirurgisch tätigem Personal (vor allem Operateuren) mit infektiöser Hepatitis-B- oder -C- oder HIV-Erkrankung, weil z. B. bei Nadelstich- oder Schnittverletzungen während der Operation Erreger auf den Patienten übertragen werden können.

\section{4 Übertragung von Patienten auf Personal}

Personal kann durch Kontakt mit infektiösen Patienten bei Nichtbeachten der erforderlichen Schutzmaßnahmen bzw. bei unerkannt infektiösen Patienten ebenfalls erkranken. Ein hohes Risiko besteht bei kontagiösen Erkrankungen, wie viralen Atemwegsinfektionen (z. B. Influenza), viralen Durchfallerkrankungen (z. B. Noroviren) oder den sog. Kinderkrankheiten, wie Masern, Mumps, Röteln, Varizellen und Pertussis, soweit keine Immunität besteht. Bei unzureichenden Basishygienemaßnahmen (mangelnde Händehygiene, künstliche Fingernägel etc.) steigt das Risiko einer Übertragung zwischen Patient und Personal drastisch an.

Nadelstichverletzungen sind trotz „safety-devices“ immer noch eine Ursache für parenteralen Blutkontakt. Dabei besteht grundsätzlich das Risiko der Übertragung einer Infektion vor allem mit HBV, HCV oder HIV. Das Transmissionsrisiko hängt zum einen von der Viruskonzentration im Blut des Patienten ab, die z. B. bei HBsAg-Trägern, die zusätzlich HBeAg-positiv sind, sehr hoch sein kann. Zum anderen spielt die inokulierte Blutmenge eine Rolle, die wiederum von der Größe der Kanüle und ihrer Eindringtiefe 
(Hohlnadel versus chirurgische Nadel) abhängt. Beim Tragen von Handschuhen wird ein Teil des Bluts abgestreift und das Infektionsrisiko dadurch verringert.

Nach einer Nadelstich- oder Schnittverletzung müssen sofort die erforderlichen Maßnahmen eingeleitet werden (vor allem gründliche Desinfektion der verletzten Haut, Einschaltung des betriebsärztlichen Dienstes zur weiteren Diagnostik und evtl. Einleitung einer Postexpositionsprophylaxe).

\section{5 Übertragung durch Kontakt}

Der direkte Kontakt zu einem kontagiösen Patienten oder zu einem Patienten, der asymptomatisch ist, aber Infektionserreger ausscheidet, ist auch in der Kinder- und Jugendmedizin der häufigste Übertragungsweg.

\section{6 Übertragung durch respiratorische Tröpfchen}

Respiratorische Tröpfchen $(>5 \mu \mathrm{m})$ werden beim Husten, Niesen und Sprechen freigesetzt. Sie haben eine Reichweite von höchstens $2 \mathrm{~m}$ und gelangen nicht in die unteren Atemwege, sondern auf die oropharyngeale Schleimhaut und die Konjunktiven.

Einige Infektionserreger werden überwiegend durch Tröpfchen übertragen, z. B. respiratory syncytial virus (RSV), Bordetella pertussis, Rötelnviren, Influenzaviren, Adenoviren, Rhinoviren, Mycoplasma pneumoniae, A-Streptokokken und Meningokokken. Diese Erreger können auch durch Kontakt mit Sekreten auf die Mund-/Nasenschleimhaut oder die Bindehaut übertragen werden.

\subsection{Aerogene Übertragung}

Damit eine Infektionsübertragung über die Luft über eine größere Distanz zustande kommt, müssen die Erreger in Form eines Aerosols vorliegen und längere Zeit in der Luft überleben können. Dies trifft insbesondere für die Erreger der Tuberkulose zu, die durch ihre lipidhaltige Zellwand vor Austrocknung geschützt sind. Unter den viralen Infektionserkrankungen ist vor allem bei Masern und Varizellen zusätzlich zur Kontakt und Tröpfchenübertragung an die Möglichkeit einer aerogenen Übertragung zu denken. Patienten, die mit solchen Erregern infiziert sind und sich in der kontagiösen Phase der Erkrankung befinden, sollen in einem Einzelzimmer, wenn möglich mit Schleuse (Doppeltür, von denen jeweils nur eine geöffnet wird) betreut werden. Das sog. Auslüften in dieser Schleuse nach Kontakt mit einem an Windpocken erkrankten Kind ist sinnlos. Es muss darauf geachtet werden, dass bei Vorliegen einer aerogen übertragbaren Erkrankung die evtl. vorhandene raumlufttechnische Anlage die Luft nicht aktiv aus dem Zimmer in Richtung Vorraum bzw. Flur befördert. Aerogen über Sporen übertragen werden auch invasive Schimmelpilzinfektionen bei hochgradig immunsupprimierten Patienten, wobei hier keine Übertragung von Mensch zu Mensch erfolgt.

\subsection{Parenterale Übertragung}

Parenterale Übertragung bedeutet, dass Erreger unter Umgehung der Schleimhäute des Verdauungstrakts und anderer Kompartimente in den Wirt gelangen. Vor allem über Blut können bei parenteralem Kontakt verschiedene Erreger übertragen werden, von denen vor allem Hepatitisviren (HBV, HCV) und HIV eine Rolle spielen. Hierunter fallen z. B. Nadelstichverletzungen (Übertragung von Patienten auf Personal, seltener auch umgekehrt). Auch Haut- und Schleimhautkontakte mit infiziertem Blut sind mit einem Infektionsrisiko verbunden, das jedoch um ca. 2-3 Zehnerpotenzen geringer ist als nach Hautverletzungen mit Kanülen oder anderen spitzen und scharfen Gegenständen. Dennoch müssen entsprechende Schutzmaßnahmen (Handschuhe) getroffen werden, wenn mit Blutkontakt an Haut oder Schleimhäuten gerechnet werden muss. In die Kategorie ,parenteral“ fallen auch Erregerübertragungen durch die Kontamination von Arzneimitteln oder Infusionslösungen zur i.v.-Behandlung.

\subsection{Fäkal-orale Übertragung}

Viele bakterielle Gastroenteritiserreger (z. B. Salmonellen, Campylobacter, Shigellen), aber auch Viren, z. B. HepatitisA- und -E-Virus, Rota- und Noroviren, sowie Parasiten werden im Stuhl ausgeschieden. Hier spielt im Gegensatz zur parenteralen Übertragung die orale Aufnahme der Erreger die entscheidende Rolle. Infizieren kann man sich einerseits direkt über die Hände bei schlechter Toilettenhygiene des Trägers, bei Diarrhöen oder Inkontinenz des Patienten durch Kontamination der Umgebung oder auch beim Windelwechsel. Eine andere Möglichkeit ist die Übertragung über einen Vektor, z. B. die Nahrung (Salmonellen, Campylobacter spp.) oder über das Trinkwasser in Ländern mit niedrigem Hygienestandard. Zur Vermeidung der fäkal-oralen Übertragung ist eine gute Händehygiene entscheidend. Im Krankenhaus bedeutet dies vor allem eine konsequente hygienische Händedesinfektion mit einem geeigneten Händedesinfektionsmittel und die Verwendung von nicht sterilen Einmalhandschuhen bei Kontakt (z. B. bei jedem Windelwechsel). 


\section{Basishygienemaßnahmen}

\subsection{Grundlagen}

Basishygienemaßnahmen werden bei allen Patienten unabhängig von ihrem Kolonisations- oder Infektionsstatus diagnoseunabhängig und damit auch bei noch fehlendem Erregernachweis durchgeführt, um eine Übertragung von Infektionserregern auf den Patienten und das Personal zu verhindern und das Risiko einer nosokomialen Weiterverbreitung von Krankheitserregern generell zu minimieren.

Hierzu gehören vor allem die hygienische Händedesinfektion, die gezielte Umgebungsdesinfektion, die fachgerechte Aufbereitung von Medizinprodukten und der situationsgerechte Einsatz von speziellen Barrieremaßnahmen (Distanzierung, Isolierung, Kohortierung) sowie sichere Injektions- und Infusionstechniken. Konsequent angewendet schützen sie auch vor Übertragung bei unerkannt mit multiresistenten Erregern besiedelten Patienten. Im weiteren Sinne zählen hierzu auch

- die Impfung von Gesundheitspersonal gegen impfpräventable übertragbare Erkrankungen,

- die Vermeidung einer Exposition von Risikopatenten gegenüber Erregern, die in komplexen Hausinstallationen im Trinkwasser vorkommen können,

- die Abschirmung von hochgradig immunsupprimierten Patienten gegenüber einer Exposition mit Schimmelpilzsporen (z. . bei Bau- oder Renovierungsarbeiten),

- die rasche Identifizierung von Krankheitserregern, z. B. von Noroviren.

Die wichtigsten Basishygienemaßnahmen werden im Weiteren beschrieben, finden sich in folgender Übersicht und im Reinigungs- und Desinfektionsplan (Tab. 1).

\section{Basishygienemaßnahmen}

- Händehygiene (vor allem Händedesinfektion mit alkoholischem Mittel)

- Gebrauch persönlicher Schutzausrüstung (PSA)

- Korrekte Handhabung und Aufbereitung von (kontaminierten) Pflegeutensilien/Medizinprodukten

- Korrekte Reinigung/Desinfektion der Patientenumgebung

- Schutz des Personals vor durch Blut übertragbaren Infektionskrankheiten

- Korrektes Verhalten bei Husten, Niesen, Schnäuzen und Toilettenbenutzung

- Sichere Injektions- und Infusionstechniken
- Diagnoseunabhängige zusätzliche Barriere bzw. Distanzierungsmaßnahmen bei Patienten, die ihre Umgebung kontaminieren (,Streupotenzial“, z. B. bei Husten oder Diarrhö) unabhängig vom Erregernachweis

\subsection{Händedesinfektion und Händewaschen}

Die Händehygiene spielt bei der Prävention nosokomialer Infektionen die entscheidende Rolle, weil die Hände des medizinischen Personals (auch die der Patienten, der Angehörigen und Besucher) der wichtigste Vektor bei der Infektionsübertragung sind. Das Ziel einer hygienischen Händedesinfektion ist die Elimination der transienten Flora, während die zusätzliche Reduktion der residenten Flora (Synonym: Standortflora) durch die chirurgische Händedesinfektion nur vor invasiven Eingriffen erforderlich ist. Beim Händewaschen mit Seife ohne Antiseptikazusatz erreicht man eine Keimreduktion um ca. $2 \log _{10}$-Stufen, beim Waschen mit antiseptischer Seife beträgt sie 2-3 $\log _{10}$ und bei der Desinfektion mit 70\%igem Isopropyl-Alkohol 3-4 $\log _{10}$-Stufen. Daher ist die Methode der Wahl für die Händehygiene die Händedesinfektion. Zudem ist die Händedesinfektion weniger zeitaufwendig und durch die rückfettenden Inhaltsstoffe besser verträglich.

$\mathrm{Zu}$ beachten ist, dass genügend Händedesinfektionsmittel verwendet wird (Faustregel: ca. $3 \mathrm{ml}$ bzw. eine gefüllte Hohlhand) und alle Hautareale (Fingerspitzen, Daumen, Fingerzwischenräume und die Querfalten der Handfläche) sicher mit einbezogen werden. Die Einreibezeit beträgt $30 \mathrm{sec}$, die genaue Einreibetechnik wird nicht mehr vorgeschrieben. Bei Schulungen durch das Hygienefachpersonal können die Mitarbeiter prüfen, ob ihre Einreibetechnik effizient ist (Schwarzlichtprobe). Es darf kein Schmuck an Händen und Unterarmen (z. B. Ringe, Armbänder, Armbanduhren) getragen werden, außerdem keine Kunstfingernägel und kein Nagellack, da sonst die Händehygiene erfahrungsgemäß nicht gründlich genug durchgeführt wird und Keimreservoire verbleiben können.

Von der WHO wurde das Konzept der 5 Momente der Händehygiene aufgestellt (http://www-who.int/gpsc/5may/ background/5moments/en/). Danach sollten zwischen Patientenkontakten grundsätzlich die Hände desinfiziert werden. Auch bei aufeinander folgenden Tätigkeiten an demselben Patienten kann eine Händedesinfektion erforderlich sein, wenn an einer Körperstelle (z. B. Blasenkatheter) eine Kon-

(Fortsetzung) 

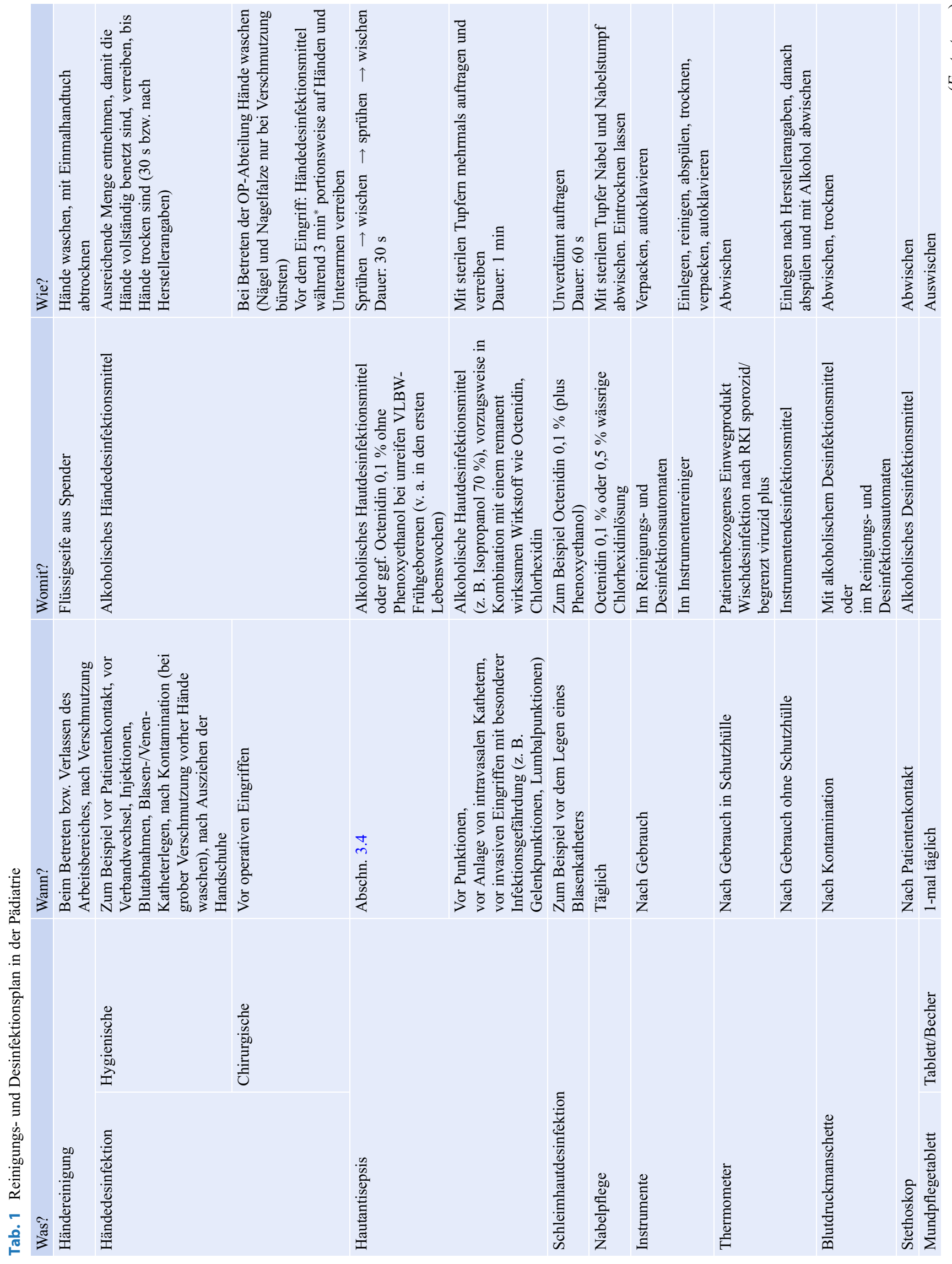


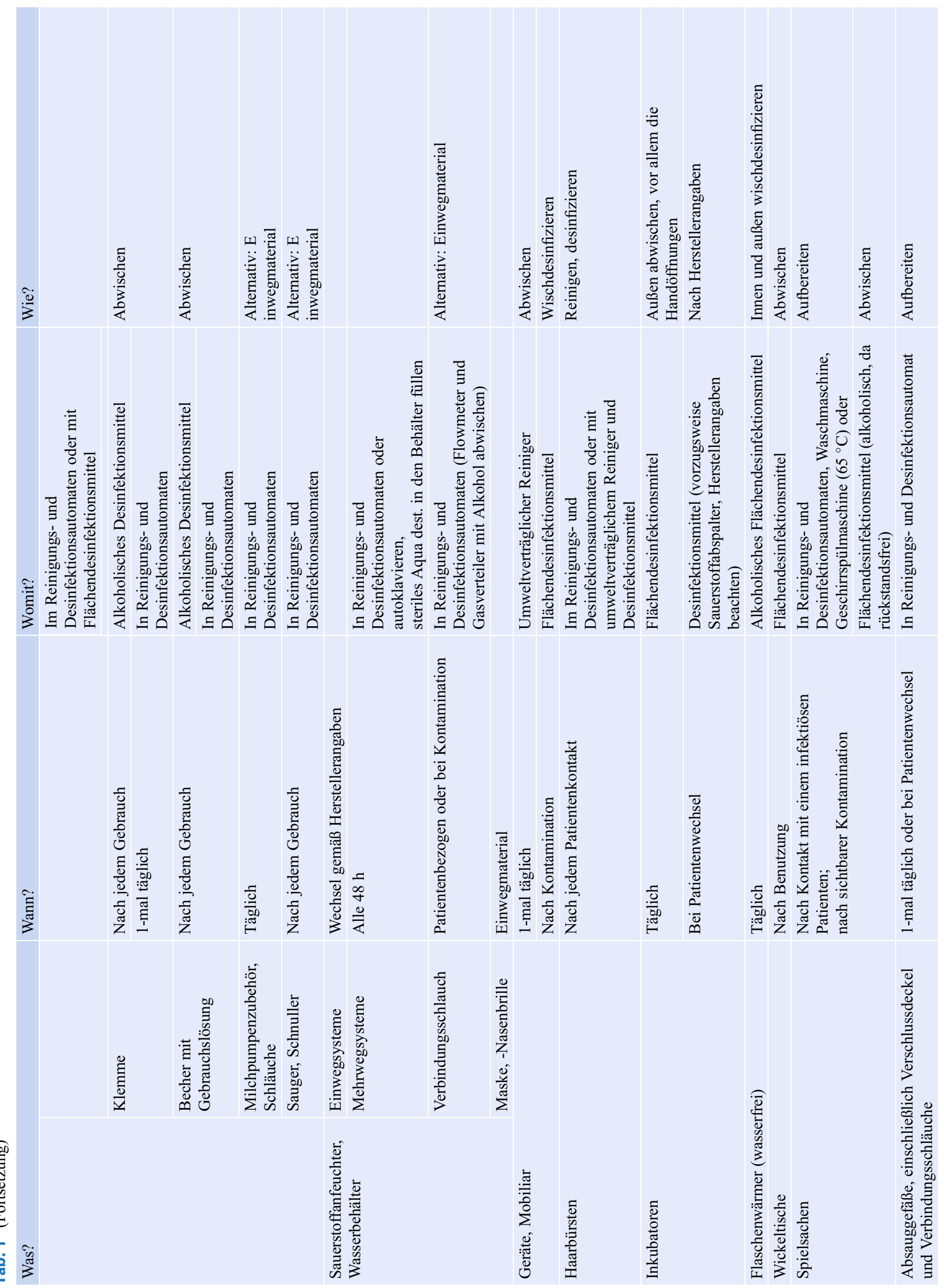



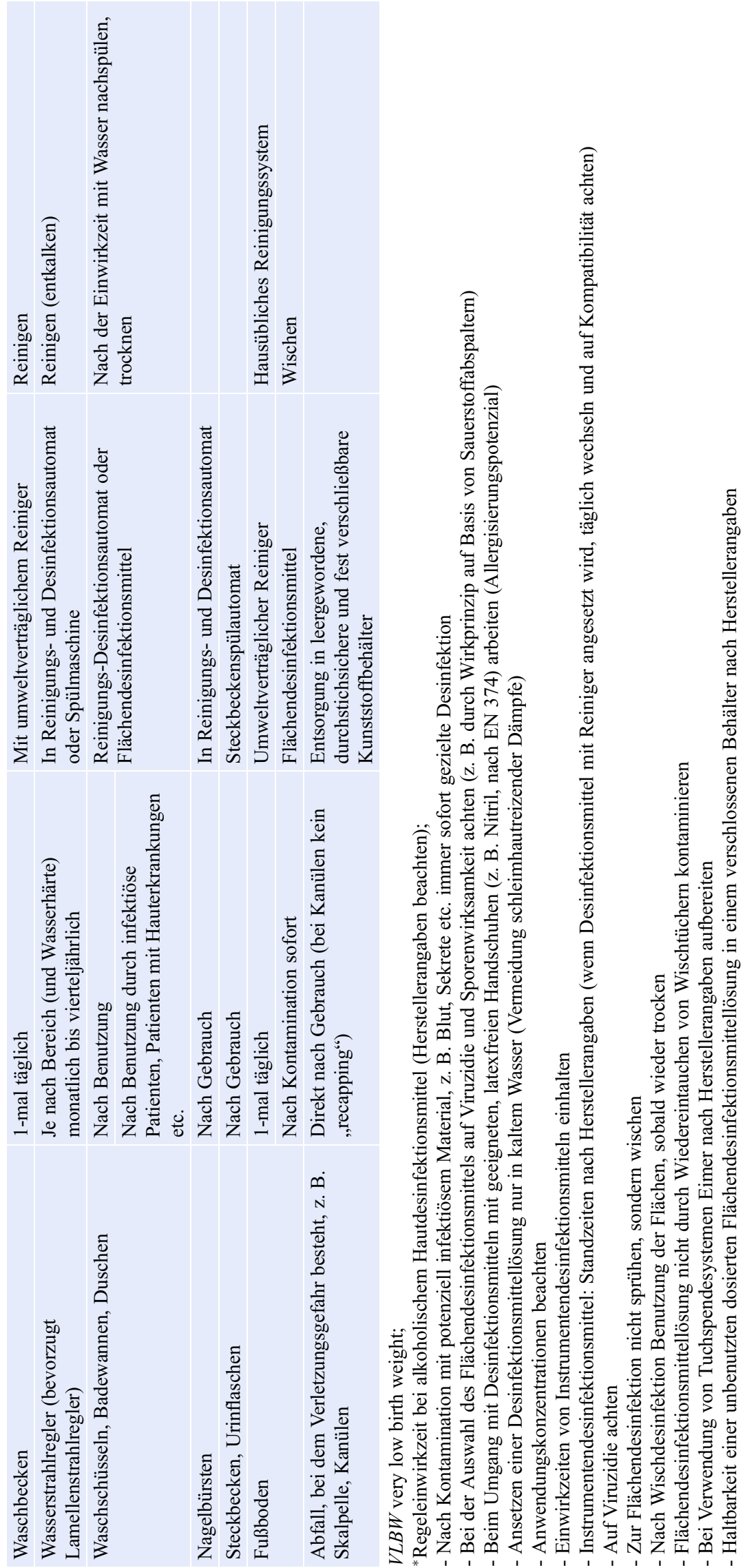
tamination stattgefunden haben kann und daran anschließend eine andere Körperstelle versorgt wird (z. B. Venenkatheter).

Das Waschen der Hände reicht in der Regel aus:

- bei Beginn bzw. Ende der Arbeit,

- nach Benutzung der Toilette,

- vor dem Essen bzw. vor dem Verteilen von Essen,

- nach dem Putzen der Nase sowie nach Husten oder Niesen mit Hand vor Mund und Nase, aber im Krankenhaus: Händedesinfektion

Die Händedesinfektion ist in den folgenden Situationen erforderlich (Abb. 1):

- vor Tätigkeiten mit Kontaminationsgefahr, z. B. Bereitstellung von Infusionen, Herstellung von Mischinfusionen, Aufziehen von Medikamenten,

- vor und nach infektionsgefährdenden Tätigkeiten, z. B. Absaugen, Verbandswechsel, Manipulationen am Venen-/ Blasenkatheter, Tracheostoma, Infusionsbesteck (auch zwischen verschiedenen Tätigkeiten bei demselben Patienten),

- vor invasiven Maßnahmen, auch wenn dabei Handschuhe (ob steril oder unsteril) getragen werden, z. B. Anlage von Venen- oder Blasenkatheter, Punktionen, Endoskopie, Angiografie,

- vor Kontakt mit abwehrgeschwächten Patienten,
- nach Kontakt mit infizierten/kolonisierten Patienten,

- nach Kontakt mit (potenziell) kontaminierten Gegenständen, z. B. Entleeren von Wasserfallen, Absauggefäß, Urinbeutel, nach Kontakt mit Blut, Exkreten, Sekreten

- nach dem Ausziehen von Einmalhandschuhen bzw. dem Ablegen von Schutzkleidung oder einem Mund-NasenSchutz.

Grundsätzlich ist eine Händedesinfektion dem Händewaschen aufgrund der höheren Keimreduktion und der besseren Hautverträglichkeit vorzuziehen. Bei Verschmutzung der Hände müssen diese aber vor der Desinfektion vorsichtig gewaschen werden. Aus Gründen des Hautschutzes sollte die Kombination von Händewaschen und Händedesinfektion auf diese Situationen beschränkt bleiben. Lediglich bei symptomatischer Infektion mit Clostridium difficile wird zusätzliches Händewaschen vor Verlassen des Zimmers empfohlen.

Auf eine gute Hautpflege sollte geachtet werden, um Hautirritationen vorzubeugen. Diese können auch durch allergische Reaktionen auf in Händedesinfektionsmitteln zum Teil noch vorkommende Parfüm- oder Farbstoffe bedingt sein. Daher sollten konsequent farb- und parfümstofffreie Händedesinfektionsmittel verwendet werden.
Abb. 15 Momente der Händehygiene (aus WHO-Leitlinien zur Händehygiene im Gesundheitswesen. https://www. aktion-sauberehaende.de/ash/ module/krankenhaeuser/5indikationen/)

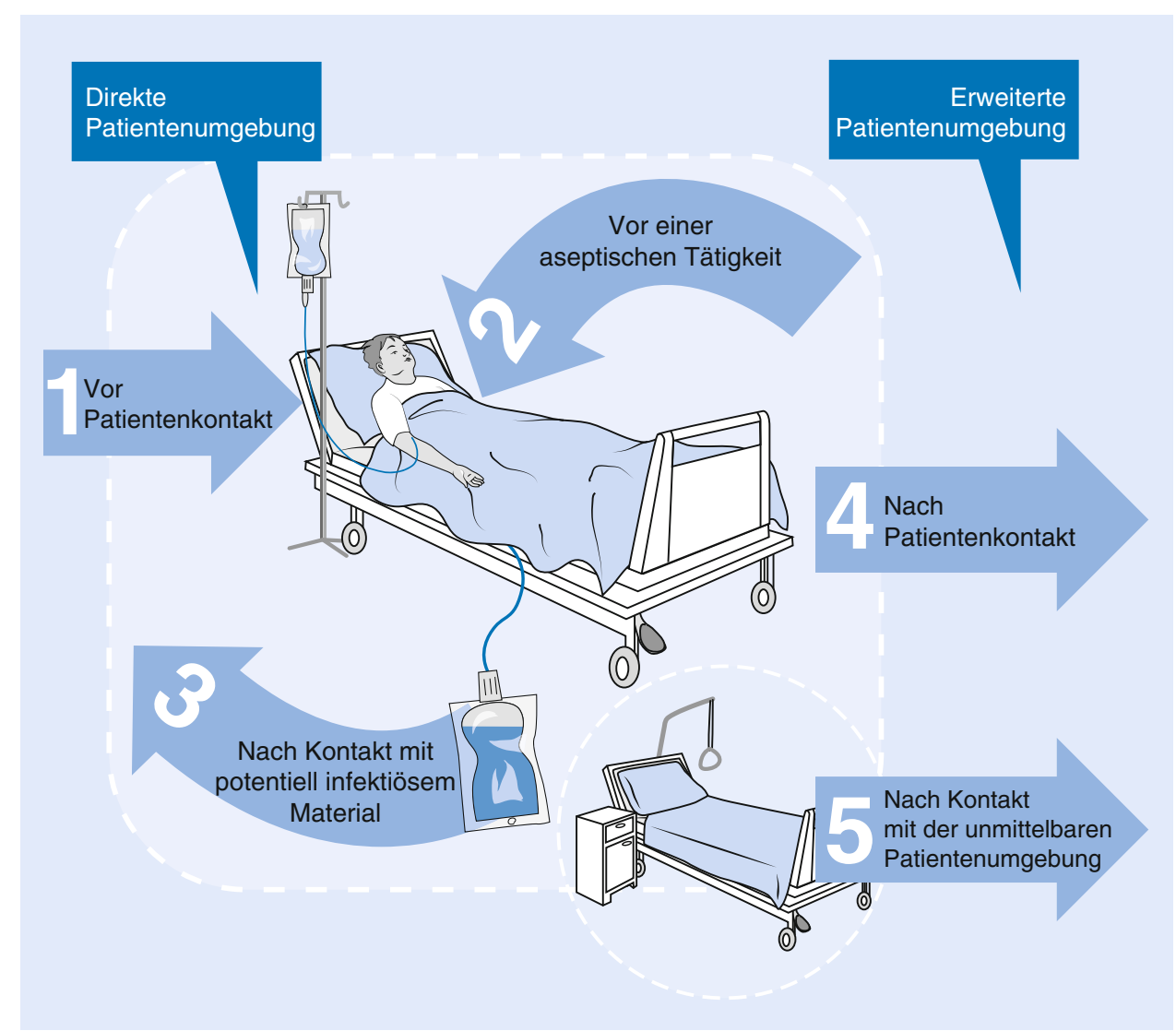




\subsection{Persönliche Schutzausrüstung (PSA)}

\section{Nichtsterile Einmalhandschuhe}

Einmalhandschuhe sollten bei möglichem Kontakt mit Blut oder anderen potenziell infektiösen Körperflüssigkeiten (Amnion-, Perikard-, Peritoneal-, Pleuraflüssigkeit, Liquor und jede mit Blut vermengte Körperflüssigkeit) getragen werden. Das Gleiche gilt für Kontakt mit Schleimhäuten und nicht intakter Haut bei allen Patienten, ferner für den Umgang mit Gegenständen oder die Berührung von Oberflächen, die mit Blut oder potenziell infektiösen Körperflüssigkeiten kontaminiert worden sind, sowie für Gefäßpunktionen und invasive Eingriffe. Bei Eingriffen in sterile Körperhöhlen müssen sterile Handschuhe getragen werden. Handschuhe sollten im Regelfall nicht an der Hand desinfiziert, sondern bei Notwendigkeit gewechselt werden. Ausnahmen von dieser Regel sind nach Prüfung (Materialauswahl: in der Regel Nitril; Desinfizierbarkeit) von der Hygienekommission festzulegen (Hinweise durch die Stellungnahme der Aktion Saubere Hände, www.aktion-sauberehaende.de). Nach dem Ausziehen der Handschuhe sollten die Hände desinfiziert werden, da die Einweghandschuhe zu einem kleinen Anteil primär undicht sind, möglicherweise undicht geworden sind bzw. weil es beim Ausziehen zu einer Kontamination der Hände gekommen sein kann.

\section{Schürze}

Schutzkittel/Schürzen werden getragen, wenn eine Kontamination der Arbeitskleidung sowie der Haut des Personals mit Blut und Körperflüssigkeiten zu erwarten ist oder auch als Nässe-Schutz. Deshalb sind sie nur dann erforderlich, wenn die Bereichskleidung oder die eigene Haut durch direkten Kontakt mit potenziell infektiösem Material kontaminiert werden kann. Sie werden außerdem im Rahmen der zusätzlichen Barrieremaßnahmen bei der Kontaktisolierung eingesetzt. Vor Verlassen der Patientenumgebung muss die Schutzkleidung abgelegt werden und es muss eine Händedesinfektion durchgeführt werden. Schutzkleidung sollte nicht wieder verwendet werden.

Die Materialeigenschaften des Schutzkittels müssen an die jeweilige Behandlungssituation angepasst sein (z. B. CE-Kennzeichnung Gruppe 3 oder DIN EN 14126).

\section{Schutzmaske, Augen- und Gesichtsschutz}

Masken und Augen- oder Gesichtsschutz sollten getragen werden, um eine Exposition der Mundschleimhaut, der Nase und der Augen bei Eingriffen zu verhindern, bei denen Blutoder Sekretspritzer entstehen können (z. B. beim Endoskopieren oder trachealen Absaugen). Ein chirurgischer Mund-Nasen-Schutz, der der Schutzklasse FFP1 entspricht, dient auch dem Schutz vor Tröpfcheninfektionen. Nur bei wenigen Infektionskrankheiten, wie bei Tuberkulose, SARSCoronavirus-Infektion oder hämorrhagischem Fieber, muss eine höherwertige Schutzmaske (FFP2 bzw. FFP3) getragen werden. Umgekehrt dient ein (chirurgischer) Mund-NasenSchutz auch dem Schutz des immunsupprimierten Kindes bei der protektiven Isolierung.

\section{Prävention von Stichverletzungen}

Durch entsprechende Sorgfalt sollen Verletzungen durch Kanülen, Skalpelle und andere scharfe Instrumente oder Gegenstände bei invasiven Eingriffen oder bei Reinigung oder Entsorgung verhindert werden. Um Nadelstichverletzungen $\mathrm{zu}$ vermeiden, darf man Kanülen niemals in die Kappe zurückstecken, von Hand umbiegen oder gar abbrechen. Nach dem Gebrauch sollten Spritzen und Kanülen, Skalpelle sowie andere scharfe Gegenstände in durchstichfesten Containern zur Entsorgung gegeben werden. Sicherheitskanülen, die das Risiko einer Nadelstichverletzung reduzieren, müssen so konsequent wie möglich verwendet werden (Arbeitsschutzanforderung Technische Regel für Biologische Arbeitsstoffe 250 [TRBA 250]).

\subsection{Punktionen und Injektionen}

Unmittelbar vor einer Punktion wird eine Hautantiseptik mit einem geeigneten Präparat unter Beachtung der vom Hersteller angegebenen Einwirkzeiten als Sprüh- oder Wischdesinfektion (je nach Art der Punktion) durchgeführt. Die Auswahl des zur Wischdesinfektion verwendeten Tupfers (keimarm oder steril) richtet sich nach der Art der Punktion und der damit verbundenen Risikoabschätzung (Tab. 2). Punktionen in der Umgebung von Hautinfektionen oder Hautschäden sollten vermieden werden. Wird eine Punktion unter Zuhilfenahme von Ultraschall durchgeführt, muss darauf geachtet werden, dass geeignete sterile Hüllen/Abdeckungen für den Ultraschallkopf verwendet werden. Zur Verbesserung der Schallqualität wird steriles Ultraschallgel oder (materialverträgliches) Hautdesinfektionsmittel empfohlen.

\subsection{Einzelzimmerunterbringung von Patienten im Rahmen der Basishygiene}

Bei Patienten, die ihre Umgebung in besonderer Weise kontaminieren (z. B. wegen Husten/Diarrhö/Erbrechen mit wahrscheinlich infektiöser Genese) müssen auch vor einem etwaigen Erregernachweis mögliche zusätzliche Übertragungswege, z. B. beim gemeinsamen Benutzen der Nasszelle oder beim Spielen berücksichtigt werden. Dann kann im Einzelfall bereits im Rahmen der Basishygienemaßnahmen eine Einzelzimmerindikation bestehen. Dies gilt unabhängig vom Resistenzverhalten der vermuteten oder nachgewiesenen Erreger. 
Tab. 2 Punktionen und Injektionen und die erforderlichen Hygienemaßnahmen (mod. nach KRINKO-Empfehlung 2011)

\begin{tabular}{|c|c|c|c|c|}
\hline Punktionsart & Tupferart & Abdeckung & $\begin{array}{l}\text { Schutzkleidung } \\
\text { durchführende Person }\end{array}$ & $\begin{array}{l}\text { Mindesteinwirkzeit bei } \\
\text { alkoholischem } \\
\text { Hautdesinfektionsmittel }^{*}\end{array}$ \\
\hline i.c.-Injektion & Keimarme & $\begin{array}{l}\text { Nicht } \\
\text { erforderlich }\end{array}$ & Nein & \multirow[t]{7}{*}{$15 \mathrm{~s}$} \\
\hline s.c.-Injektion durch medizinisches Personal & Keimarme & $\begin{array}{l}\text { Nicht } \\
\text { erforderlich }\end{array}$ & Nein & \\
\hline Lanzettenblutentnahme & Keimarme & $\begin{array}{l}\text { Nicht } \\
\text { erforderlich }\end{array}$ & Keimarme Handschuhe & \\
\hline Blutabnahme & Keimarme & $\begin{array}{l}\text { Nicht } \\
\text { erforderlich }\end{array}$ & Keimarme Handschuhe & \\
\hline i.v.-Injektion (peripher) & Keimarme & $\begin{array}{l}\text { Nicht } \\
\text { erforderlich }\end{array}$ & Keimarme Handschuhe & \\
\hline i.m.-Injektion (z. B. Schutzimpfung) & Keimarme & $\begin{array}{l}\text { Nicht } \\
\text { erforderlich }\end{array}$ & Nein & \\
\hline Akupunktur & Keimarme & $\begin{array}{l}\text { Nicht } \\
\text { erforderlich }\end{array}$ & Nein & \\
\hline s.c.-Punktion mit nachfolgender Dauerapplikation & Sterile & $\begin{array}{l}\text { Nicht } \\
\text { erforderlich }\end{array}$ & Keimarme Handschuhe & \multirow[t]{8}{*}{$30 \mathrm{~s}$} \\
\hline $\begin{array}{l}\text { i.m.-Injektion (Risikopatient, Injektion von } \\
\text { Kortikoiden oder gewebstoxischen Substanzen) }\end{array}$ & Sterile & $\begin{array}{l}\text { Nicht } \\
\text { erforderlich }\end{array}$ & Keimarme Handschuhe & \\
\hline Shunt-Punktion zur Dialyse (autologer Shunt) & Sterile & $\begin{array}{l}\text { Nicht } \\
\text { erforderlich }\end{array}$ & Keimarme Handschuhe & \\
\hline Punktion einer Portkammer & Sterile & $\begin{array}{l}\text { Nicht } \\
\text { erforderlich }\end{array}$ & Sterile Handschuhe & \\
\hline Lumbalpunktion (diagnostisch) & Sterile & $\begin{array}{l}\text { Steriles } \\
\text { Abdeck- oder } \\
\text { Lochtuch }\end{array}$ & $\begin{array}{l}\text { Sterile Handschuhe } \\
\text { Mund-Nasen-Schutz }\end{array}$ & \\
\hline Punktion eines Ommaya- oder Rickham-Reservoirs & Sterile & $\begin{array}{l}\text { Nicht } \\
\text { erforderlich }\end{array}$ & $\begin{array}{l}\text { Sterile Handschuhe } \\
\text { Mund-Nasen-Schutz bei } \\
\text { Punktion mit } \\
\text { Spritzenwechsel }\end{array}$ & \\
\hline Blasenpunktion (diagnostisch) & Sterile & $\begin{array}{l}\text { Nicht } \\
\text { erforderlich }\end{array}$ & Sterile Handschuhe & \\
\hline Pleurapunktion, Aszitespunktion (diagnostisch) & Sterile & $\begin{array}{l}\text { Nicht } \\
\text { erforderlich }\end{array}$ & $\begin{array}{l}\text { Sterile Handschuhe } \\
\text { Mund-Nasen-Schutz }\end{array}$ & \\
\hline Beckenkammpunktion & Sterile & $\begin{array}{l}\text { Steriles } \\
\text { Abdeck- oder } \\
\text { Lochtuch }\end{array}$ & Sterile Handschuhe & \multirow[t]{7}{*}{$60 \mathrm{~s}$} \\
\hline $\begin{array}{l}\text { Organpunktion (z. B. Niere, Leber, Lymphknoten, } \\
\text { Milz, Schilddrüse) }\end{array}$ & Sterile & $\begin{array}{l}\text { Steriles } \\
\text { Abdeck- oder } \\
\text { Lochtuch }\end{array}$ & Sterile Handschuhe & \\
\hline Anlage einer suprapubischen Ableitung & Sterile & $\begin{array}{l}\text { Steriles } \\
\text { Abdeck- oder } \\
\text { Lochtuch }\end{array}$ & $\begin{array}{l}\text { Sterile Handschuhe } \\
\text { Mund-Nasen-Schutz }\end{array}$ & \\
\hline $\begin{array}{l}\text { Spinalanästhesie (Single shot), intrathekale } \\
\text { Medikamentenapplikation }\end{array}$ & Sterile & $\begin{array}{l}\text { Steriles } \\
\text { Abdeck- oder } \\
\text { Lochtuch }\end{array}$ & $\begin{array}{l}\text { Sterile Handschuhe } \\
\text { Mund-Nasen-Schutz }\end{array}$ & \\
\hline Gelenkpunktion (diagnostisch) & Sterile & $\begin{array}{l}\text { Steriles } \\
\text { Abdeck- oder } \\
\text { Lochtuch }\end{array}$ & $\begin{array}{l}\text { Sterile Handschuhe } \\
\text { Mund-Nasen-Schutz }\end{array}$ & \\
\hline $\begin{array}{l}\text { Anlage einer Bülau-Drainage, eines Pleuracath, } \\
\text { einer Monaldi-Drainage }\end{array}$ & Sterile & $\begin{array}{l}\text { Steriles } \\
\text { Abdeck- oder } \\
\text { Lochtuch }\end{array}$ & $\begin{array}{l}\text { Mund-Nasen-Schutz } \\
\text { OP-Haube } \\
\text { steriler langärmeliger } \\
\text { Kittel } \\
\text { sterile Handschuhe }\end{array}$ & \\
\hline $\begin{array}{l}\text { Periduralanästhesie/Spinalanästhesie mit } \\
\text { Katheteranlage, Anlage eines Periduralkatheters zur } \\
\text { Schmerztherapie }\end{array}$ & Sterile & $\begin{array}{l}\text { Steriles } \\
\text { Abdeck- oder } \\
\text { Lochtuch }\end{array}$ & $\begin{array}{l}\text { Mund-Nasen-Schutz } \\
\text { OP-Haube } \\
\text { steriler langärmeliger }\end{array}$ & \\
\hline
\end{tabular}


Tab. 2 (Fortsetzung)

\begin{tabular}{|c|c|c|c|c|}
\hline Punktionsart & Tupferart & Abdeckung & $\begin{array}{l}\text { Schutzkleidung } \\
\text { durchführende Person }\end{array}$ & $\begin{array}{l}\text { Mindesteinwirkzeit bei } \\
\text { alkoholischem } \\
\text { Hautdesinfektionsmittel* }\end{array}$ \\
\hline & & & $\begin{array}{l}\text { Kittel } \\
\text { sterile Handschuhe }\end{array}$ & \\
\hline $\begin{array}{l}\text { Perkutane endoskopische Gastrostomie-Anlage } \\
\text { (PEG) }\end{array}$ & Sterile & $\begin{array}{l}\text { Steriles } \\
\text { Abdeck- oder } \\
\text { Lochtuch }\end{array}$ & $\begin{array}{l}\text { Mund-Nasen-Schutz } \\
\text { OP-Haube } \\
\text { steriler langärmeliger } \\
\text { Kittel } \\
\text { sterile Handschuhe }\end{array}$ & \\
\hline
\end{tabular}

*Herstellerangaben beachten; zur speziellen Hautantiseptik bei Neu- und Frühgeborenen, Abschn. 8;

KRINKO Kommission für Krankenhaushygiene und Infektionsprävention

\section{$4 \quad$ Diagnosespezifisch erweiterte Schutzmaßnahmen}

Sie sind dann notwendig, wenn Infektionen und/oder Kolonisationen diagnostiziert oder auch begründet anzunehmen sind, bei denen ein Übertragungsrisiko trotz der Einhaltung der Basishygienemaßnahmen besteht (Abschn. 4.1, Übersicht „Kontaktübertragungen“).

Die hier folgende Übersicht listet die betreffenden Erreger mit Einstufung in die entsprechenden Schutzmaßnahmen auf.

Übersicht über erregerspezifische Schutzmaßnahmen (mod. nach Schulz-Stübner 2017; KRINKO 2015; Siegel et al. 2007)

S: „standard precautions“ - Basishygiene

C: ,contact precautions“ - Kontaktschutzmaßnahmen

D: „droplet precautions“ - Schutzmaßnahmen vor Tröpfcheninfektionen

A: ,airborne precautions“ - Schutzmaßnahmen vor Übertragungen durch die Luft

- Abszess mit unkontrollierter Drainage und Streupotenzial: $\mathrm{C}$

- Askariose: S

- Clostridium-difficile-Infektion: C (bis 2 Tage nach Sistieren des Durchfalles, Handschuhe und gegebenenfalls Händewaschen zusätzlich zur alkoholischen Händedesinfektion; Sauerstoffabspalter zur Flächendesinfektion)

- CMV: S (keine Zusatzmaßnahmen, auch bei schwangerem Personal)

- Diphtherie (kutan): C (bis 2 Kulturen im Abstand von 24 Stunden negativ)

- Diphtherie (pharyngeal): D (bis 2 Kulturen im Abstand von 24 Stunden negativ)

- Enteroviren (Coxsackie A und B, Echoviren): C (bei „Streupotenzial“ und in Ausbruchssituationen)

(Fortsetzung)
- Furunkulose mit CA-MRSA und PVL-positiven MSSA: C (Dekolonisierung anstreben)

- Rotavirus-Enteritis: C (bis 2 Tage nach Ende der Symptome, viruzides Desinfektionsmittel einsetzen)

- Norovirus-Enteritis D (bis 2 Tage nach Ende der Symptome); Norovirus-wirksames Desinfektionsmittel einsetzen

- Hepatitis A und E: C (bis 2 Wochen nach Auftreten des Ikterus)

- Hepatitis B,C,D:

- S (doppelte Handschuhe bei Stich- und Schnittverletzungsrisiko)

- C (in kinderonkologischen Abteilungen vor allem bei Patienten mit aktiver Virusreplikation)

- Herpes neonatorum: C (bis Läsionen verkrustet)

- Herpes simplex (schwere Hautaffektionen, disseminiert): C (bis Läsionen verkrustet)

- Hepes-simplex-Enzephalitis: S

- Herpes zoster (generalisiert): C (bis Läsionen verkrustet)

- Humanes Metapneumovirus: C

- Impetigo contagiosa (meist Streptococcus pyogenes, Staphylococcus aureus): C (24 Stunden nach Therapiebeginn)

- Influenza: D (7 Tage; bei immunkompromittierten Patienten für die Dauer des Aufenthaltes)

- Kongenitale Röteln:

- C (bis zum 1. Lebensjahr)

- S (wenn nasopharyngeale Abstriche und Urinkultur negativ nach 3 Lebensmonaten)

- Konjunktivitis (bakteriell, Chlamydien, Gonokokken): S

- Keratokonjunktivitis epidemica: C (meist Adenovirus, hochinfektiös, viruzides Desinfektionsmittel einsetzen)

- Krätze (Scabies): C (bis 24 Stunden nach Therapiebeginn, bei Scabies crustosa Aufhebung der spezi-

(Fortsetzung) 
ellen Hygienemaßnahmen nach dermatologischer Kontrolluntersuchung, in der Regel nach 14 Tagen)

- Läuse: C (bis 24 Stunden nach Therapiebeginn; Sichtkontrolle)

- Masern: A, C (bis 5 Tage nach Auftreten des Exanthems, für den gesamten Aufenthalt bei Immunsuppression)

- Meningitis:

- Viral, fungal, Listeria monocytogenes, Streptococcus pneumoniae, Mycobacterium tuberculosis, gramnegative Erreger: $\mathrm{S}$

- Neisseria meningitidis (Meningokokken)

- Haemophilus influenzae Typ b: D (bis 24 Stunden nach Therapiebeginn, Postexpositionsprophylaxe bei ungeschütztem engem Kontakt zu respiratorischen Sekreten)

- Meningokokkensepsis oder -pneumonie: D (bis 24 Stunden nach Therapiebeginn, Postexpositionsprophylaxe bei ungeschütztem engem Kontakt zu respiratorischen Sekreten)

- MERS: A, C (bis 48 Stunden nach Sistieren der Symptomatik)

- MRE (MRSA, VRE, GISA, multiresistente gramnegative Erreger [MRGN]): Streupotenzial berücksichtigen, Abschn. 4.4

- Molluscum contagiosum (Dellwarzen): S

- Mumps: D (für 9 Tage)

- Mycoplasma pneumoniae: D

- Nekrotisierende Enterocolitis (NEC): S (bei ausbruchsähnlicher Situation: C)

- Parainfluenzavirus: C

- Parvovirus B 19 (Erythema infectiosum): D

- Pertussis (Keuchhusten): D (bis 5 Tage nach Beginn einer effektiven antibiotischen Therapie bzw. 3 Wochen nach Beginn der Hustensymptomatik)

- Pneumonie:

- Adenoviren: D

- Burkholderia cepacia: bei Mukoviszidose mit Exazerbation einer Atemwegsinfektion und/oder chronischer Besiedlung der Atemwege mit Staph. aureus, P. aeruginosa, B.-cepacia-Komplex: C

- Staphylococcal scalded skin syndrome (Morbus Ritter von Rittershain): C

- Poliomyelitis: $\mathrm{C}$

- Rhinovirus: D

- Roseola infantum (Exanthema subitum durch humanes Herpesvirus 6): S

- Röteln:
- D (für 7 Tage nach Auftreten des Exanthems)

- Zusatzmaßnahmen bei Exposition ungeimpfter Kontaktpersonen: 5 Tage D, Impfung innerhalb von 3 Tagen nach Exposition bei nicht schwangeren Exponierten, Beschäftigungsverbot für Personal im Gesundheitswesen bis zum 21. Tag nach Exposition

- RSV (respiratory syncytial virus): D (besonderes Risiko für Frühgeborene und Kinder mit angeborenen hämodynamisch relevanten Herzfehlern und Kinder mit schwerer neuromuskulärer Beeinträchtigung)

- Streptococcus-Gruppe A (GAS):

- In großen Wundflächen: C (bis 24 Stunden nach Therapiebeginn oder wenn keine adäquate Wundabdeckung möglich ist)

- Pharyngitis: D (bis 24 Stunden nach Therapiebeginn)

- Pneumonie: D (bis 24 Stunden nach Therapiebeginn)

- Scharlach: D (bis 24 Stunden nach Therapiebeginn)

- Streptococcus-Gruppe B (GBS) und andere: S

- Tuberkulose:

- Extrapulmonal ohne Sekretion: S

- Extrapulmonal mit Sekretion: A, C (bis 3 mikroskopisch negative Abstriche, entnommen im Abstand von je 24 Stunden, vorliegen)

- Pulmonal: A (bis 3 mikroskopisch negative Sputum- oder Magensaftproben, entnommen im Abstand von je 24 Stunden, vorliegen)

- Virales hämorrhagisches Fieber (z. B. Lass-, Ebola-, Marburg-, Krim-Kongo-Fieber): D (besondere Schutzmaßnahmen auf Sonderisolierstationen)

- Windpocken:

- A, C (bis Läsionen verkrustet)

- Herpes zoster (generalisiert): C (bis Läsionen verkrustet)

- Zoster (Isolierzimmer ohne Schleuse)

\subsection{Kontaktschutzmaßnahmen („,contact precautions")}

Der Unterschied zur Basishygiene besteht in der erweiterten Verwendung von Schutzkleidung und der zusätzlichen räumlichen Distanzierung. Auch im Einzelzimmer braucht es die Basishygienemaßnahmen, da die indirekte Verbindung zu den anderen Patienten über das Personal bestehen bleibt. 


\section{Kontaktübertragungen}

Die den Basishygienemaßnahmen entsprechenden Empfehlungen werden durch folgende zusätzliche Maßnahmen erweitert:

- Einzelzimmerunterbringung mit eigener Toilette

- Handschuhe: Tragen von Handschuhen bei direktem Kontakt mit dem Patienten oder der Patientenumgebung/Handkontaktflächen. Vor aseptischen Tätigkeiten am Patienten frische Handschuhe anziehen. Bei möglichem Kontakt mit infektiösem Material, d. h. auch im Zimmer des mit MRE besiedelten Patienten jeweils tätigkeitsbezogen

- Schutzkittel: Tragen eines geeigneten Schutzkittels bei direktem Kontakt mit dem Patienten, d. h. bei Möglichkeit der Kontamination der Bereichs- oder Dienstkleidung

- Schutzkleidung nach Beendigung der Tätigkeit bzw. bei Verlassen des Patientenzimmers entsorgen, dabei Kontamination von Haut und Kleidung vermeiden

- Mund-Nasen-Schutz, Augenschutz: Tragen eines Mund-Nasen-Schutz und Augenschutz, wenn mit dem Verspritzen von potenziell infektiösem Material gerechnet werden muss (z. B. Erbrechen, Absaugen usw.) oder bei Betreten des Patientenzimmers (z. B. bei Noroviren, Masern)

Angehörige und Besucher sollten auf das Übertragungsrisiko hingewiesen und in die korrekte Nutzung der Schutzausrüstung und die Händedesinfektion eingeführt werden (Übersicht „Kontaktübertragungen“).

Geräte werden durchgängig patientenbezogen eingesetzt oder zwischen der Anwendung bei verschiedenen Patienten sachgerecht aufbereitet.

Wäsche, die nicht sichtbar mit infektiösem Material (z. B. Stuhl) kontaminiert ist, wird im Zimmer im normalen Wäschesack gesammelt. Lediglich massiv mit infektiösem Material kontaminierte Wäsche (z. B. Stuhl) wird im Zimmer separat in einen geschlossenen Wäschesack gegeben und bei Gefahr der Durchfeuchtung mit einem zusätzlichen Plastiksack in die Wäscherei transportiert, wo sie entsprechend der Unfallverhütungsvorschriften (UVV) als sog. infektiöse Wäsche separat gewaschen wird.

Abfall, der massiv mit infektiösem Material kontaminiert ist, wird getrennt gesammelt und als sog. infektiöser Müll (AS 180103 ) entsorgt.

\section{Transport und Verlegung}

Ein etwaiger Transport erfolgt unter Beibehaltung der oben genannten Barrieremaßnahmen nach Information der Zieleinrichtung.

\section{Reinigung/Flächendesinfektion}

Patientennahe, insbesondere häufig berührte Flächen werden täglich im Rahmen der laufenden sowie bei Entlassung oder Verlegung als Schlussdesinfektion unter Einbeziehung des Fußbodens wischdesinfiziert. Das dabei eingesetzte Desinfektionsmittel muss gegen den Erreger (und bei Clostridium difficile auch gegen Sporen) wirksam sein (z. B. auf Basis eines Sauerstoffabspalters). Erregerspezifische Festlegungen werden von der Krankenhaushygiene und der Hygienekommission getroffen und möglichst in Form eines erregerspezifischen Hygienedatenblatts zur Verfügung gestellt.

\subsection{Schutzmaßnahmen vor Tröpfcheninfektionen}

Von den aerogen übertragenen Infektionen wie z. B. Tuberkulose unterschieden werden müssen diejenigen Erkrankungen, die durch erregerhaltige größere Tröpfchen respiratorischen Sekrets durch Kontakt oder durch die Luft über kurze Distanzen übertragen werden (bei engem Kontakt [,face-to-face"] bis 1,5 m Abstand). Indikationen für zusätzliche Schutzmaßnahmen (,droplet precations") und obligate Einzelzimmerunterbringung oder Kohortenisolierung sind unter Abschn. 4, Übersicht „Übersicht über erregerspezifische Schutzmaßnahmen“ als diagnosespezifische, erweiterte Schutzmaßnahmen aufgeführt.

Das Personal sollte bei nahem Patientenkontakt $(<2 \mathrm{~m})$ einen chirurgischen Mund-Nasen-Schutz tragen. Außerhalb des Zimmers sollten die Kinder ebenfalls einen MundNasen-Schutz tragen, der inzwischen in kindgerechtem Design in verschiedenen Kindergrößen verfügbar ist. $\mathrm{Zu}-$ sätzlich sollten Handschuhe und evtl. auch ein Schutzkittel getragen werden, wenn Kontakt mit infektiösem Material (in der Regel Atemwegssekrete, aber auch Handkontaktflächen in der Umgebung des Patienten) möglich ist. Bei Infektionen, bei denen eine antibiotische Therapie möglich ist, kann die Isolierung in der Regel nach 24 Stunden wieder aufgehoben werden (z. B. Gruppe-A-Streptokokken, Pneumokokken, Meningokokken). Bei Erkrankungen wie Windpocken oder Masern sollte grundsätzlich immunes Personal eingesetzt werden. 


\subsection{Schutzmaßnahmen vor aerogenen Übertragungen}

Werden beim Husten oder Niesen größere Tröpfchen in die Luft abgegeben, verdunstet die äußere Schicht der Tropfen, und zurück bleiben Tröpchenkerne mit einer Größe $<5$ microm. Diese können in der Luft schweben und so Erreger auch über weitere Strecken transportieren.

$\mathrm{Zu}$ den fast ausschließlich aerogen übertragbaren Infektionen gehört die offene Lungentuberkulose. Varizellen, Masern und auch Influenza-Infektionen können sowohl durch Kontakt als auch aerogen übertragen werden.

\section{Offene Lungentuberkulose}

Kriterium für die sog. offene Tuberkulose und damit die Isolierung eines Patienten ist der mikroskopische Nachweis von Mykobakterien im Sputum bzw. Magensaft. Kinder mit offener Lungentuberkulose sind im Gegensatz zu Erwachsenen weniger infektiös, da die Erregerzahl, die ausgeschieden wird, gering ist. Eine Isolierung von Säuglingen und Kleinkindern mit Verdacht auf eine Tuberkulose-Erkrankung ist daher in der Regel nicht gerechtfertigt. Dennoch sollten bei Kindern ab Schulalter mit offener Lungentuberkulose die gleichen Isolierungsmaßnahmen wie bei Erwachsenen durchgeführt werden. Das Kind sollte in einem Einzelzimmer mit idealer Weise bei MDR/XDR Tbc raumlufttechnischer Anlage (6-12 Luftwechsel/h) und negativem Druck im Vergleich zu den angrenzenden Räumen untergebracht werden. Die Abluft muss entweder nach außen abgeführt oder bei Umluftbetrieb durch einen Schwebstofffilter geführt werden, wobei die Tür geschlossen bleiben muss. Ist keine raumlufttechnische Anlage vorhanden, ist das Vorhandensein eines Vorraums (Doppeltür, von denen jeweils nur eine geöffnet wird) günstig. Es sollte eine häufige Fensterlüftung erfolgen. Dabei muss darauf geachtet werden, dass sich keine Personen in der Lüftungszone befinden.

Das Personal muss bei Betreten des Zimmers eine gut sitzende, partikelfiltrierende Halbmaske der Filterstufe FFP2 oder FFP3 möglichst mit Ausatemventil anlegen. Bei Verlassen des Zimmers sollte den Kindern wenn möglich ein passender Mund-Nasen-Schutz angelegt werden.

\subsection{Besonderheiten bei multiresistenten Erregern}

\section{Methicillin-resistente Staphylococcus aureus (MRSA)}

MRSA besitzen im Vergleich zu methicillin-sensiblen Staph. aureus (MSSA) zwar eine vergleichbare Virulenz, sind aber schwieriger behandelbar und führen abhängig vom jeweiligen Stamm häufiger zu Infektionen bei Intensivpatienten. Sogenannte CA-MRSA (community acquired MRSA) dagegen verursachen Infektionen auch bei sonst gesunden Kindern.

Bei Kindern liegt der MRSA-Anteil bei Staphylococcus aureus erfahrungsgemäß deutlich niedriger als der bei Erwachsenen beschriebene Anteil von 10-15\%. Betroffen sind vor allem chronisch kranke Kinder mit längeren Krankenhausaufenthalten und häufigen Antibiotikatherapien (z. B. Patienten mit zystischer Fibrose).

Hauptreservoir von Staph. aureus (MRSA und MSSA) als Besiedler von Haut und Schleimhäuten ist der NasenRachen-Raum. Die Übertragung erfolgt hauptsächlich über die Hände. Da auch bei einem MRSA-Screening ein relevanter Teil der besiedelten Patienten unerkannt bleibt, müssen bei allen Patienten, unabhängig vom Infektionsstatus die Regeln der Basishygiene beachtet werden. Diese sind grundsätzlich geeignet, Übertragungen von MRSA wie auch MSSA zu verhindern. Schutzkittel oder Plastikschürzen dienen der Vermeidung der Kontamination der Arbeits- bzw. Bereichskleidung bei Tätigkeiten, bei denen mit Kontakt mit potenziell infektiösem Patientenmaterial (auch Hautschuppen) zu rechnen ist, z. B. beim Bettenmachen, Umlagern, Waschen oder während der Physiotherapie. Die Auswahl langärmeliger Schutzkittel versus Plastikschürze ist dabei abhängig vom erwarteten Ausmaß der Kontamination und einer evtl. zu erwartenden Durchfeuchtung. Ein MundNasen-Schutz ist bei engem Kontakt erforderlich, wenn das besiedelte Kind eine Atemwegsinfektion aufweist, beim endotrachealen Absaugen (gegebenenfalls zusätzlich Schutzbrille), beim Verbandswechsel bei ausgedehnter Wundinfektion bzw. immer bei Gefahr des Verspritzens von infektiösem Material (Basishygiene).

\section{Einzelzimmerunterbringung}

Eine Unterbringung im Einzelzimmer erleichtert die konsequente Einhaltung der Basishygienemaßnahmen und wird in der stationären Behandlung von MRSA-positiven Kindern und Jugendlichen allgemein empfohlen, muss aber im Einzelfall abgewogen werden. Dies ist vor allem dann zu erwägen, wenn die Kinder die Regeln der Basishygiene noch nicht einhalten können. Einer psychosozialen Isolierung muss jedoch entgegen gewirkt werden. Dies gelingt ohne Aufgabe hygienischer Sicherheit für das Personal durch den tätigkeitsbezogenen Einsatz der Schutzmaßnahmen (Handschuhe, Schutzkittel und Mund-Nasen-Schutz) strikt nach den Regeln der Basishygiene.

Medizinisch indizierte Transporte und diagnostische Maßnahmen können unter Einhaltung analog der im Zimmer erforderlichen tätigkeitsbezogenen Schutzmaßnahmen und einer 
Flächendesinfektion von Kontaktflächen wie Rollstühlen, Liegen oder Röntgenplatten jederzeit durchgeführt werden.

Besucher benötigen Schutzkittel dann, wenn sie aktiv in die Pflege mit eingebunden werden oder ein hohes Kontaminationsrisiko der Kleidung besteht. Die obligate Händedesinfektion vor Verlassen des Zimmers sollte durch das Pflegepersonal erklärt werden. Kinder sollen aus medizinischen und psychosozialen Gründen grundsätzlich im Krankenhaus von einer engen Vertrauensperson (meist von einem Elternteil) begleitet werden. Bei Kindern mit kontagiösen Erkrankungen ist, insofern die Eltern keine Immunität aufweisen, von einer stattgehabten Erregerübertragung auf die Eltern auszugehen. Die Kinder werden deshalb zusammen mit ihrem begleitenden Elternteil isoliert. Wenn die Eltern das Isolierzimmer verlassen, müssen erregerspezifisch Vorkehrungen getroffen werden, damit es auf der Station nicht zu einer Übertragung auf andere Personen kommt. In Absprache mit dem Patienten (oder seinen Angehörigen/Sorgeberechtigten) ist die Anzahl der Besucher so zu begrenzen, dass die zusätzlichen Aufgaben für das Behandlungsteam (Einweisung in die Händehygiene, Anamnese bezüglich Risikofaktoren auf Seiten des Besuchers, gegebenenfalls Einweisung in Barrieremaßnahmen) tatsächlich geleistet werden können.

Die über die Basishygiene hinaus gehenden Maßnahmen können aufgehoben werden bei Wegfall der zur Isolierung führenden Indikation.

\section{Dekolonisierungsbehandlung}

Bei Kindern, die mit MRSA besiedelt sind, kann ergänzend eine Dekolonisierung zur Erregerlastreduktion des an der Haut oder Schleimhaut besiedelten Patienten angestrebt werden (http://www.mrsa-kinder.net/). Ein Problem in Bezug auf einen dauerhaften Dekolonisierungserfolg besteht darin, dass Säuglinge und Kleinkinder den Erreger häufiger auch im Nasopharynx und im Gastrointestinaltrakt tragen, wo antiseptische Waschungen und die nasale Dekolonisationsbehandlung nicht wirksam sind. Grundsätzlich kann aus einem 1-mal negativen Screeningergebnis nur auf eine aktuelle MRSA-Suppression mit Reduktion des Übertragungsrisikos geschlossen werden.

Die nachhaltige Wirksamkeit der Maßnahmen zur Dekolonisierung von MRSA-Trägern hinsichtlich der Minderung des individuellen (Staphylokokken-)Infektionsrisikos ist jedoch nicht belegt und sollte deshalb im Einzelfall unter Berücksichtigung von Risikofaktoren (Störung der Mikrobiomentwicklung vs. besondere Empfänglichkeit gegenüber Staphylokokkeninfektionen durch Immunsuppression, geplante Eingriffe usw.) entschieden werden. Insofern muss bei ansonsten gesunden Kindern (inklusive Neugeborene) ohne Risikofaktoren nicht routinemäßig eine Dekolonisationsbehandlung durchgeführt werden.

\section{MRSA-Screening}

Regelhaft auf MRSA sollten unter anderem alle Patienten untersucht werden, die schon einmal mit MRSA besiedelt oder infiziert waren bzw. bei denen ein Familienmitglied betroffen ist. Dialysepflichtige Patienten können hinsichtlich der Rate an Infektionskomplikationen von einer Dekolonisierung direkt profitieren. Grundsätzlich sollte erwogen werden, Kinder bei Krankenhausaufnahme auf MRSA zu screenen, wenn sie aus Intensivabteilungen anderer Krankenhäuser verlegt werden, in ihrer Anamnese rezidivierende stationäre Aufenthalte mit Antibiotikatherapie haben oder aus einem Land mit hoher MRSA-Prävalenz stammen bzw. sich (in den letzten Monaten) dort aufgehalten haben. caMRSA werden häufiger bei Kindern und Jugendlichen gefunden, die zuvor in U.S.-amerikanischen Gesundheitseinrichtungen des Militärs behandelt wurden.

\section{Community-acquired MRSA (caMRSA)}

Seit einigen Jahren werden weltweit auch MRSA bei Personen nachgewiesen, bei denen keine für nosokomiale MRSA typischen Risikofaktoren wie Krankenhausaufenthalte, Antibiotikatherapien oder schwere Grunderkrankungen vorliegen. Diese sog. community-aquired MRSA (caMRSA, auch CA-MRSA) verursachen typischerweise invasive Haut- und Weichteilinfektionen (Furunkulosen, Abszesse bis hin zur nekrotisierenden Fasziitis) selten auch nekrotisierende Pneumonien, z. B. nach einer Influenzaerkrankung. ca-MRSA weisen häufig außer einer Oxacillin-Resistenz nur wenige andere Resistenzen auf und sind mitunter noch Clindamycin-sensibel. Die in Deutschland, der Schweiz und Frankreich isolierten Stämme sind außerdem typischerweise resistent gegen Fusidinsäure. Es ist möglich (wie in den U.S.A. und anderen Ländern beschrieben), dass caMRSA in die Krankenhäuser hineingetragen werden und dort Ausbrüche verursachen. Die erforderlichen Hygienemaßnahmen sind die gleichen wie bei den herkömmlichen MRSA. Aufgrund der höheren Virulenz (u. a. Produktion des Toxins Panton-Valentine-Leukozidin, das eine Porenbildung in neutrophilen Granulozyten bewirkt) sollte auch bei gesunden Personen, die ins Krankenhaus aufgenommen werden müssen oder in Gesundheitsberufen arbeiten oder anderen Risikofaktoren, bei Besiedlung mit caMRSA der Versuch einer Dekolonisierung unternommen werden. 


\section{Maßnahmen bei Infektion oder Kolonisation mit Vancomycin-resistenten Enterokokken}

Vancomycin-resistente Enterokokken (VRE) sind durch das sogenannte Van-A- oder das Van-B-Gen gegen Glycopeptide resistent (VRE mit Van-B sind in vitro oft Teicoplanin-sensibel, das trotzdem nicht zur Therapie von VRE-Infektionen eingesetzt werden sollte). VRE sind - da meist E. faecium - nahezu immer resistent gegen Ampicillin. Infektionen treten fast ausschließlich bei Kindern mit schweren Grunderkrankungen oder hochgradiger Immunsuppression sowie nach Lebertransplantation auf. Zur Häufigkeit von VRE-Infektionen bei Kindern in Deutschland fehlen bislang valide Daten, bei intensivmedizinisch behandelten Früh und Neugeborenen werden sie nur sehr selten als Infektionserreger beobachtet (NEO-KISS, http://www.nrz-hygiene.de/surveillance/kiss/neo-kiss/; KISS, Krankenhaus-Infektions-Surveillance-Systems). Das Erregerreservoir von VRE ist der Magendarmtrakt, VRE lassen sich jedoch auch auf der Haut, an den Händen und in der Umgebung von kolonisierten Patienten nachweisen. Die Übertragung erfolgt hauptsächlich mit den Händen (plus Handkontaktflächen) sowie über kontaminierte Medizinprodukte und Gegenstände (Toilette!); Dies gilt besonders für Räume, in denen Patienten mit Diarrhö gepflegt werden.

Die Übertragung von VRE sollte in der Pädiatrie durch Isolierungsmaßnahmen analog derer bei MRSA verhindert werden. Durch die Unterbringung von VRE-positiven Patienten in Einzelzimmern bzw. durch Kohortenisolierung und durch Tragen von Handschuhen und Schutzkitteln konnten Ausbruchsituationen bei Erwachsenen beendet werden, wobei in den meisten Fällen zusätzlich die Umgebungsdesinfektion deutlich intensiviert und supervidiert wurde.

Die Kolonisation mit VRE persistiert langfristig. Daher sind wiederholte Abstrichuntersuchungen während eines Krankenhausaufenthalts nutzlos.

\section{ESBL-bildende Bakterien und andere multiresistente gramnegative Erreger (MRGN)}

Diverse Extended-spectrum- $\beta$-Laktamasen (ESBL) vermitteln bei Klebsiella spp., E. coli, Citrobacter spp., Enterobacter spp., Serratia spp. und anderen gramnegativen Enterobakterien Resistenzen gegenüber $\beta$-Laktam-Antibiotika. Besonders problematisch ist das Auftreten zusätzlicher plasmid- oder transposongebundener Resistenzgene gegenüber Carbapenemen und Chinolonen und die Weitergabe der resistenzvermittelnden Plasmide auf Enterobakterien einer anderen Spezies. Solche Erreger haben beim Einsatz vieler Antibiotika, die in der Pädiatrie als Erstlinientherapie in den entsprechenden Leitlinien der Fachgesellschaften aufgeführt sind, einen Selektionsvorteil. Bei schwerkranken Patienten steigt das Risiko für einen komplizierten oder sogar fatalen Verlauf, wenn die initial gewählte empirische (kalkulierte) Therapie einer systemischen Infektion unwirksam ist. Neben dem möglichst gezielten, restriktiven und leitlinienkonformen Einsatz von Antibiotika sollte daher bei der Auswahl der kalkulierten Therapie berücksichtigt werden, ob der Patient mit MRGN kolonisiert ist, wobei bei einer Infektion dann tatsächlich nachgewiesene Erreger nicht immer mit den Kolonisationskeimen identisch sind.

Primär aus krankenhaushygienischer Perspektive hat die KRINKO (Kommission für Krankenhaushygiene und Infektionsprävention) multiresistente gramnegative Erreger aufgrund ihrer Resistenzeigenschaften gegenüber mehreren Antibiotikaklassen wie in Tab. 3 dargestellt eingeteilt. Bei Kindern sind Fluorchinolone nicht in der empirischen Therapie zugelassen, sodass bereits eine Resistenz gegen Piperacillin und Cephalosporine der Gruppe 3 oder 4 bei erhaltener in-vitro-Wirksamkeit von Fluorochinolonen und Carbapenemen zur Einstufung in die Kategorie 2MRGN „NeoPäd“ führt. Diese Erreger sind die am häufigsten in der Pädiatrie nachgewiesenen MRGN. Transmissionen sind bei strikter Einhaltung der Basishygiene unter Verwendung von Einmalhandschuhen und Schutzkitteln bei zu erwartendem Kontakt mit infektiösem Material vermeidbar bzw. nicht häufiger als bei antibiotikaempfindlichen Erregern. Eine Einzelzimmerisolierung ist daher in der Regel nicht erforderlich (Ausnahme Streupotenzial durch Husten/Diarrhö bei größeren Kindern; Tab. 3).

\section{Multiresistente und anderweitig problematische Erreger auf neonatologischen Intensivstationen}

Insbesondere ESBL-bildende Klebsiella pneumoniae, aber auch die anderen oben genannten Enterobakterien können endemische nosokomiale Besiedlungen/Infektionen bis hin zu klonalen Ausbruchssituationen beispielsweise auf neonatologischen Intensivstationen verursachen.

Das häufigste Erregerreservoir stellt der Gastrointestinaltrakt besiedelter Patienten dar. Die Übertragung erfolgt meist über die Hände und sekundär über Reservoire in der Patientenumgebung. Daraus ergibt sich die konsequente Einhaltung der Basishygienemaßnahmen (Abschn. 3) als wichtigstes Präventionskonzept in Verbindung mit wirksamer Flächenreinigung und -desinfektion. Eine darüber hinaus gehende räumliche Distanzierung wird nach den beschriebenen Kriterien (Abschn. 4.4, „Methicillin-resistente Staphylococcus aureus (MRSA)“ vorgenommen. Bei Patienten, die mit 4MRGN besiedelt oder infiziert sind, soll das Pflegepersonal in angemessener Zahl so zugeordnet werden, dass es nicht gleichzeitig andere Patienten betreut, die nicht mit solchen Erregern kolonisiert oder infiziert sind.

Eine Übersicht der Hygienemaßnahmen beim Personal zeigt folgende Übersicht. 


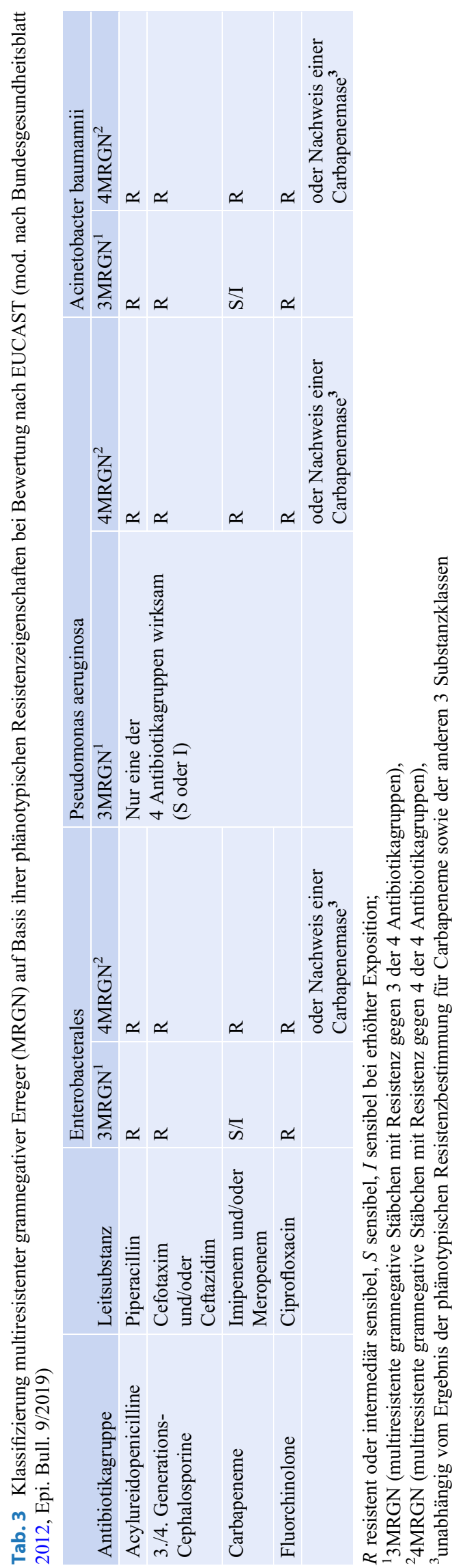


Hygienemaßnahmen des Personals beim Umgang mit MRE-positiven Patienten (mod. nach Schulz-Stübner

2017)

- Strikte Einhaltung der Basishygiene

- Einmalhandschuhe nach den Regeln der Standardhygiene verwenden. Handschuhe ausziehen, wenn Tätigkeit beendet, danach Händedesinfektion

- Vor Verlassen des Patientenzimmers sollte unabhängig davon, ob Patientenkontakt stattgefunden hat oder nicht, eine hygienische Händedesinfektion durchgeführt werden, da evtl. unbemerkt eine Kontamination der Hände durch Kontakt mit kontaminierten Flächen erfolgt ist

- Für übliche pflegerische Tätigkeiten, bei denen die Gefahr der Durchfeuchtung der Arbeitskleidung besteht, flüssigkeitsdichte Schürzen und langärmeligen Schutzkittel verwenden

- Wenn mit Kontamination der Arbeitskleidung mit infektiösem Material zu rechnen ist, Schutzkittel verwenden

- Tragen von Schutzkitteln beim Betreten des Zimmers ohne geplanten Patientenkontakt (z. B. Abstellen eines Tabletts, Blick in die Kurve und Patientengespräch) in der Regel nicht erforderlich

- Wenn Gefahr des Verspritzens von infektiösem Material besteht, Atemschutz und Schutzbrille tragen

Neben der regelmäßigen Diskussion von abteilungsbezogenen Erreger- und Resistenzstatistiken muss das Behandlungsteam zusammen mit dem Hygienefachpersonal verfolgen, ob bestimmte MRGN (aber auch unabhängig davon auffällige Erreger insgesamt) in zeitlichem und räumlichen Zusammenhang nachgewiesen werden.

Die Infektionssurveillance nach NEO-KISS (oder ITS-KISS bei pädiatrischen Intensivpatienten) ist jedoch nicht zur zeitnahen Erkennung von Ausbrüchen geeignet. MRSA und MRGN werden bei intensivmedizinisch behandelten Früh- und Neugeborenen in einem wöchentlichen Kolonisationsscreening gesucht. Die Ergebnisse sollen einmal wöchentlich interdisziplinär diskutiert werden (Kliniker, Krankenhaushygieniker, Mikrobiologe, z. B. bei infektiologischen Visiten). Der Nutzen dieses Screenings ist allerdings nicht unumstritten.

Wichtige Punkte für die Krankenhaushygiene

- Micro-Cluster von Kolonisationen mit krankenhaushygienisch und infektiologisch bedeutsamen Erregern werden durch das Kolonisationsscreening bei intensivmedizinisch behandelten Früh- und Neugeborenen vermehrt zur Kenntnis genommen. Bislang ist nicht wissenschaftlich belegt, dass dieses von der KRINKO vorgegebene Konzept des Kolonisationsscreenings zu einer Reduktion von nosokomialen Infektionen führt. Die zunehmende Erfahrung mit den regional unterschiedlichen Besiedlungsmustern erleichtert jedoch die Beurteilung der abteilungsspezifischen Epidemiologie. Erweiterte Barrieremaßnahmen in diesem Zusammenhang sollen in enger Absprache mit der Krankenhaushygiene erfolgen. Dies gilt auch für die Entscheidung, eine molekulargenetische Typisierung der Isolate vorzunehmen, um einen Zusammenhang zwischen den Nachweisen bei mehreren Patienten zu belegen oder auszuschließen.

- Übertragungen erfolgen vorwiegend über die Hände des Personals.

- Bei einem ungünstigen Pflegeschlüssel (Überbelegung, zu wenig qualifiziertes und vor Ort gut eingearbeitetes Personal) steigt die Rate an Übertragungen von MRE und nosokomialen Infektionen erheblich an.

- Zur Begrenzung der Weiterverbreitung ist ein gezielter, restriktiver und leitlinienkonformer Antibiotika-Einsatz von noch größerer Bedeutung als bei MRSA und VRE.

- Krankenhaushygienisch problematisch, d. h. leichter übertragbar und verantwortlich für schwerwiegende NI, sind Serratia marcescens, Klebsiella spp. und P. aeruginosa, unabhängig vom Grad der Resistenz.

- Eine Besiedlung Frühgeborener auf neonatologischen Intensivstationen erfolgt nach wenigen Tagen mit stationsspezifischer Flora:

- Hauptreservoir von MRGN in Hochrisikoabteilungen sind besiedelte oder infizierte Mitpatienten.

- Es besteht ein Zusammenhang zwischen gastrointestinaler Kolonisation von Frühgeborenen mit gramnegativen Erregern und späteren Blutkulturisolaten einer Late-onset-Sepsis, insbesondere bei E. cloacae, K. pneumoniae und S. marcescens. Der Anteil der besiedelten Kinder, die im Verlauf eine Infektion erleiden, ist bei S. marcescens am höchsten.

- Transport von Patienten mit MRE

- Der Transport erfolgt nach den Regeln für die im Zimmer geltenden Schutzmaßnahmen.

- Personal der Zieleinrichtung informieren! 


\section{5}

\section{Desinfektion und Reinigung}

\subsection{Art der Desinfektionsmittel}

Tab. 1 gibt einen Überblick über die in der Pädiatrie durchzuführenden Reinigungs- und Desinfektionsmaßnahmen.

Obwohl der Grundsatz gilt, thermische Desinfektionsverfahren nach Möglichkeit den chemischen vorzuziehen, gibt es auch in der Pädiatrie weiterhin Indikationen für den Einsatz chemischer Desinfektionsmittel für Geräte und Gegenstände, die nicht mit thermischen Methoden desinfiziert werden können. Aldehydische Mittel werden aufgrund ihres irritativtoxischen Potenzials kontrovers beurteilt und dürfen nach Risikobeurteilung nur noch eingesetzt werden, wenn es keine gleichwertige Alternative gibt (Technische Regel für Gefahrstoffe [TRGS] 540). Mittel auf Basis von Sauerstoffabspaltern verfügen gegenüber beispielsweise quaternären Ammoniumverbindungen meist über ein breiteres Wirkspektrum, z. B. bestimmte Viren und Sporen von Clostridium difficile. Prinzipiell aber müssen chemische Desinfektionsmaßnahmen wegen ihres toxischen Potenzials gegenüber Patienten, Personal, aber auch der Umwelt auf ein notwendiges und sinnvolles Maß reduziert werden. Vollautomatische thermische Desinfektionsverfahren sind sowohl hinsichtlich ihrer Desinfektionssicherheit als auch ihrer Reinigungsleistung und ferner ihrer Standardisierbarkeit wo immer möglich vorzuziehen.

\subsection{Besonderheiten}

\section{Spielsachen}

Eine routinemäßige Desinfektion von Spielzeug ist nicht erforderlich (Ausnahmen: pädiatrische Onkologie, CF-Patienten). Es sollte jedoch vorzugsweise abwaschbares Spielzeug verwendet werden, das mit einem umweltverträglichen Reinigungsmittel oder maschinell gereinigt werden kann. Unmittelbar nach offenkundiger Kontamination mit potenziell infektiösem Material, z. B. Blut, werden Spielsachen nach Reinigung und Trocknung mit alkoholischem Flächendesinfektionsmittel abgewischt, sofern sie nicht maschinell waschbar sind. Plüsch- und Kuscheltiere sollten jedoch grundsätzlich bei $60^{\circ} \mathrm{C}$ in der Waschmaschine waschbar sein, falls sie wegen einer Kontamination oder z. B. nach Kontakt mit einem infektiösen Kind aufbereitet werden müssen.

\section{Bettwäsche, Kinderkleidung}

Wäsche (Strampler, Bettwäsche) wird als Krankenhauswäsche oder in kleinem Umfang im pädiatrischen Bereich gewaschen. Generell sind die krankenhausüblichen überprüften Waschverfahren z. B. bei $60{ }^{\circ} \mathrm{C}$ mit Vollwaschmittel (Bleichkomponente) anzuwenden. Zusätzliche Desinfektionsmittel sind gegebenenfalls bei niedrigeren Waschtemperaturen erforderlich.

\section{Anforderungen an die Raumlufttechnik}

Für die Stationen der pädiatrischen Abteilung mit reifen Neugeborenen und Kinder gelten grundsätzlich die gleichen Anforderungen an die Raumluft wie in den anderen Abteilungen einer Klinik. In der Regel werden die Patientenzimmer wie die der Erwachsenenabteilungen - sofern sie mechanisch belüftet werden - nach Raumklasse 2 (DIN 1946-4:2008) belüftet.

Gemäß der Anforderungen der KRINKO auf Stationen mit neonatologischen Intensivpflegepatienten mit einem Geburtsgewicht $<1500 \mathrm{~g}$ soll ein Intensivbehandlungszimmer für Frühgeborene voll klimatisiert sein. Für die Luftauslässe der Inkubatoren und von Beatmungsgeräten werden HEPA-Filter empfohlen.

Bau-, Umbau- und Renovierungsmaßnahmen mit Abriss-, Schleif- und/oder Erdarbeiten in der Umgebung der neonatologischen Intensivpflegestation (NIPS) können zu einem massiven Eintrag von Aspergillus-Sporen führen und eine Infektionsgefahr für Frühgeborene darstellen. Die Bauleitung ist daher zu verpflichten, vorsorglich sowohl das Hygienefachpersonal sowie die Abteilungs- und Stationsleitung über die geplanten Maßnahmen frühzeitig zu informieren. Obgleich von Seiten der KRINKO für die NIPS eine generelle Empfehlung zur HEPA-Filtrierung der Zuluft nicht ausgesprochen wird, wird während der Zeit der Baumaßnahmen zur Prävention des Eintrags von Aspergillus-Sporen eine Abschirmung durch HEPA-Filtrierung der Zuluft empfohlen. Hierzu kann auch der Einsatz mobiler HEPA-Filter erwogen werden. Das Gleiche gilt insbesondere auch für kinderonkologische Patienten mit Granulozytopenie.

\section{Infektionen des Respirationstrakts}

\subsection{Virusinfektionen des Respirationstrakts}

$\mathrm{Zu}$ diesen Infektionen, Kap. $\vee$ „Respiratorische Viren bei Kindern und Jugendlichen".

Viren verursachen ca. $10 \%$ aller nosokomialen Atemwegsinfektionen. Am häufigsten kommen RS-, Parainfluenza-, humane Metapneumo- (hMPV), Adeno-, Rhino- und Influenzaviren vor. Diese Infektionen stehen zeitlich mit dem Auftreten der jeweiligen Virusstämme in der Bevölkerung in Zusammenhang. Daher schwankt auch die Inzidenz der nosokomial erworbenen Krankheiten saisonal. Praktisch alle Patienten, Besucher und auch das Personal unterliegen einem Infektionsrisiko und/oder können eine Infektionsquelle darstellen.

Viren des Respirationstrakts können von Mensch zu Mensch durch Tröpfcheninfektion oder durch kontaminierte Hände übertragen werden. Entgegen der früheren Konvention sollte man die Kinder daher dazu anhalten, sich beim Husten und Niesen abzuwenden und auf den Boden bzw. in die Ellenbeuge zu niesen. 
Virale Atemwegsinfektionen weisen hinsichtlich der Infektionsprävention Besonderheiten auf: In der Erkältungszeit sind viele Menschen in der Bevölkerung infiziert, sodass nicht nur Patienten, sondern auch Besucher und Personal Erreger zum Teil asymptomatisch ins Krankenhaus tragen. Eine zuverlässige und schnelle Virusdiagnostik ist oft nicht verfügbar. Daher gelten für alle Patienten mit Symptomen viraler Atemwegsinfektionen die Schutzmaßnahmen gegen Übertragungen durch respiratorische Tröpfchen (Abschn. 4.2). Wenn aufgrund von Platzproblemen eine Einzelzimmerunterbringung nicht möglich ist, sollte auf einen ausreichenden $(2 \mathrm{~m})$ Abstand der Betten geachtet werden und bei möglicher Kontamination besonderer Wert auf die korrekte Händedesinfektion und den Gebrauch von Handschuhen gelegt werden. Besucher und insbesondere auch besuchende Kinder müssen auf Infektionen orientierend klinisch untersucht werden. In einer Ausbruchssituation sollten elektive Aufnahmen von Risikopatienten nach Möglichkeit verschoben werden. Bei Influenza-Infektionen sollte grundsätzlich eine Einzelzimmerunterbringung bzw. Kohortierung erfolgen. Klinisch kaum umsetzbar ist eine Trennung bzw. Kohortierung nach unterschiedlichen Influenzaviren, obwohl theoretische Überlegungen für die Trennung von Influenza A und Influenza B sprechen könnten.

\subsection{Häufige Erreger}

\section{Influenzaviren}

Influenzaviren können auf glatten Oberflächen bis zu 2 Tage überleben und können daher von unbelebten Flächen aufgenommen werden. Typischerweise scheidet ein nicht unerheblicher Teil der Patienten asymptomatisch oder oligosymptomatisch Influenzaviren aus. Nosokomiale Ausbrüche werden nicht selten durch unterschiedliche Virusstämme verursacht, wobei oft ein Stamm dominiert.

\section{Wichtiger Hinweis}

Alle Mitarbeiter in der Pädiatrie sollten sich jährlich gegen Influenza impfen lassen (tetravalenter Impfstoff), sowohl zum Eigenschutz als auch um eine Übertragung auf die betreuten Patienten zu vermeiden.

\section{Respiratory syncytial virus (RSV)}

Außerhalb des Körpers kann man RS-Viren noch bis zu 7 Stunden nachweisen. In den ersten 2 Lebensjahren machen nahezu alle Kinder eine RSV-Primärinfektion durch. Die Übertragung erfolgt entweder direkt bei engem Kontakt durch Tröpfcheninfektion oder indirekt über die Hände des Personals oder durch Kontakt mit Oberflächen, die mit respiratorischem Sekret kontaminiert wurden. Die Schleimhäute der Nase und der Augen sind die hauptsächlichen Eintrittspforten. Das Personal kann sich selbst infizieren, z. B. wenn es sich mit den Händen ins Gesicht oder in die Augen fasst. Die Infektion hinterlässt keine lang anhaltende Immunität. In der Bevölkerung können unterschiedliche RSV-Serotypen gleichzeitig zirkulieren. Bei bestimmten Hochrisikokindern besteht nach den Vorgaben einer Konsensusempfehlung der Fachgesellschaften in den ersten beiden Lebensjahren die Möglichkeit einer passiven Immunisierung mit Palivizumab. Jedoch können auch mit Palivizumab immunisierte Kinder eine RSV-Infektion durchmachen und den Erreger ausscheiden/übertragen.

\section{Parainfluenza}

Meist wechseln sich verschiedene Serotypen bei Ausbrüchen im Herbst und Winter jeden Jahres ab. Während dieser Ausbruchsperioden sind dann andere respiratorische Viren in der Bevölkerung wesentlich seltener nachzuweisen. Die Übertragung erfolgt durch respiratorische Tröpfchen oder direkten Kontakt. Bei der subglottischen stenosierenden Laryngotracheitis ist Parainfluenza der häufigste Erreger.

\section{Adenoviren}

Adenoviren sind als unbehüllte DNA-Viren gegenüber Umgebungsfaktoren und Desinfektionsmaßnahmen besonders stabil und tolerieren Temperaturen zwischen $4-36{ }^{\circ} \mathrm{C}$ sowie einen weiten $\mathrm{pH}-$ Bereich. Der Übertragungsweg ist vor allem bei jüngeren Kindern fäkal-oral, kann aber auch über Tröpfchen erfolgen (Atemwegsinfektionen). Die Kontagiosität ist hoch: Bei 46-67 \% aller Kontakte im Haushalt oder Kindergarten kommt es zu einer Infektion.

\section{Rhinoviren}

Rhinoviren sind unbehüllte RNA-Viren, die ebenfalls langsamer durch Alkohole zu inaktivieren sind als behüllte Viren. Sie können auf Oberflächen bis zu 3 Stunden infektiös bleiben. Die Übertragung erfolgt überwiegend über die Hände, aber auch über respiratorische Tröpfchen. Das Virus wird hauptsächlich über Nasensekret für etwa 2-3 Wochen ausgeschieden. Asthmaexazerbationen bei Schulkindern werden oft durch Rhinoviren getriggert.

\subsection{Bakterielle Infektionen des oberen Respirationstrakts}

\section{A-Streptokokken}

A-Streptokokken sind die häufigsten bakteriellen Erreger und verursachen $20-40 \%$ aller Tonsillopharyngitiden bei Kindern ab dem 4. Lebensjahr. Wichtig sind die leitliniengerechte klinische und mikrobiologische Diagnose (Antigentest, Kultur) und bei Nachweis von A-Streptokokken die Empfehlung einer antibiotischen Behandlung mit Penicillin. 
Der Patient ist 24 Stunden nach Beginn einer effektiven Antibiotikatherapie nicht mehr infektiös. Asymptomatische Kontaktpersonen werden nicht untersucht und nicht behandelt. Bei invasiven GAS-Infektionen wird eine antibiotische Prophylaxe für Haushaltskontaktpersonen empfohlen (Kap. >,Bakterielle Infektionen bei Kindern und Jugendlichen: grampositive und gramnegative Kokken“").

\section{Diphtherie}

Patienten mit laryngealer oder pharyngealer Diphtherie müssen isoliert werden, bis 3 aufeinander folgende Abstriche von Nase und Rachen negativ sind. Patienten mit Hautdiphtherie sollten kontaktisoliert werden, bis 3 Hautkulturen negativ sind. Bei Kontaktpersonen müssen unabhängig vom Impfstatus Abstriche entnommen und eine antibiotische Prophylaxe durchgeführt werden (Kap. > ,Bakterielle Infektionen bei Kindern und Jugendlichen: grampositive Stäbchen“).

\section{Pertussis}

Keuchhusten betrifft nicht nur Säuglinge und Kleinkinder, sondern in den letzten Jahren auch vermehrt Jugendliche und Erwachsene. Insbesondere erkrankte Erwachsene, häufig mit atypischer klinischer Symptomatik, und stellen wiederum eine wichtige Erregerquelle für gefährdete, sehr junge Säuglinge dar, die altersbedingt noch keinen wirksamen Impfschutz besitzen. Dokumentierte Ausbruchssituationen legen eine konsequente Immunisierung aller Mitarbeiter in Pädiatrie und Neonatologie nahe (Auffrischung alle 10 Jahre). Die STIKO empfiehlt jedem Erwachsenen, der innerhalb der letzten 10 Jahre keine Pertussis-Impfung erhalten hat, die einmalige Auffrischung mit einem dTap-Impfstoff (Kap. „Impfungen und Reiseimpfungen bei Kindern und Jugendlichen“). Bei Aufnahme eines Kindes wegen Keuchhustens sollte eine antibiotische Therapie mit einem Makrolid begonnen werden (Kap. „Bakterielle Infektionen bei Kindern und Jugendlichen: gramnegative Stäbchen“). Dadurch wird zwar der Verlauf der Krankheit nur bedingt beeinflusst (abhängig vom Zeitpunkt der Gabe), der Patient verliert jedoch innerhalb von 5 Tagen seine Infektiosität.

\section{Offene Lungentuberkulose}

Kriterium für die sog. offene Tuberkulose und damit die Isolierung eines Patienten ist der mikroskopische Nachweis von Mykobakterien im Sputum bzw. Magensaft. Kinder mit Tuberkulose der Lunge sind deutlich weniger kontagiös als erwachsene Patienten. Sie entwickeln meist geschlossene, verkäsende Läsionen und selten Kavernen, die Anschluss an das Bronchialsystem finden. Letzteres sowie ein ausreichend starker Hustenstoß ist eine Voraussetzung für die Ausscheidung von Tuberkelerregern (offene Lungentuberkulose). Meist muss man daher die Infektionsquelle bei älteren Familienangehörigen oder erwachsenen Kontaktpersonen suchen. Eine Isolierung von Säuglingen und Kleinkindern mit Verdacht auf Tuberkulose-Erkrankung ist in der Regel nicht gerechtfertigt. Dennoch sollten bei Kindern ab Schulalter mit offener Lungentuberkulose trotz der geringeren Kontagiosität im Krankenhaus die gleichen Isolierungsmaßnahmen empfohlen werden wie bei Erwachsenen (Einzelzimmer, Masken mindestens der Filterstufe FFP2 beim Betreten des Raumes). Umgekehrt sind Kinder, insbesondere Säuglinge, besonders infektionsanfällig. Nach möglicher Exposition muss daher nach entsprechender Diagnostik eine medikamentöse Prophylaxe oder eine präemptive Therapie erwogen werden (Kap. \,Atypische bakterielle Infektionen bei Kindern und Jugendlichen“").

\section{Weitere nosokomiale Infektionen}

\subsection{Pneumonie}

Nosokomiale Pneumonien haben einen Anteil von 15-20\% an der Gesamtzahl nosokomialer Infektionen bei Säuglingen und Kleinkindern. Obwohl einige dieser Infektionen über eine hämatogene Aussaat zustande kommen, spielen in den meisten Fällen Mikroaspirationen der endogenen bakteriellen Flora aus dem Oropharynx und seltener aus dem Magen unter künstlicher Beatmung die wichtigste pathogenetische Rolle. In den ersten 4 Tagen nach Intubation verändert sich diese Flora und weist dann die typischen Hospitalkeime auf (siehe unten). Wichtigste Risikofaktoren einer Pneumonie sind die maschinelle Beatmung mit endotrachealer Intubation und die Therapie mit Breitspektrumantibiotika, die zu einer Selektion multiresistenter Erreger führen kann. Medikamente, die zu einer Erhöhung des Magensaft-pH-Werts führen (insbesondere Protonenpumpenhemmer und $\mathrm{H}_{2}$-Rezeptorenblocker), erhöhen das Risiko einer beatmungsassoziierten Pneumonie, weil sich im Magensaft ab einem $\mathrm{pH}$ von ca. 4,0 grampositive und gramnegative Keime vermehren können.

Häufige Erreger nosokomialer bakterieller Pneumonien sind: Pseudomonas aeruginosa, Staph. aureus (selten auch MRSA), Haemophilus influenzae, Escherichia coli und Klebsiella pneumoniae.

Bei der Prävention der nosokomialen Pneumonie ist die strikte Beachtung der Basishygiene entscheidend (Abschn. 3; zur Besiedlung mit MRE Abschn. 4.4). Medikamentenvernebler dürfen nur mit sterilen Flüssigkeiten gefüllt werden. Beim Entleeren von Wasserfallen müssen Handschuhe getragen werden. Endotracheales Absaugen muss unter aseptischen Bedingungen erfolgen. Sind die Atemwege mit MRE besiedelt, wird eine geschlossene Absaugung empfohlen. Auch für Kleinkinder gibt es inzwischen Trachealtuben, die mit niedrigem Druck und breit aufsitzendem Cuff geblockt werden können. 


\section{Ambulant erworbene Pneumonie}

Bei Säuglingen und Kleinkindern, die in den Wintermonaten mit einer akuten Atemwegsinfektion stationär aufgenommen werden, sollte zumindest eine Testung auf RSV (Isolierung) und Influenza (Isolierung) erfolgen.

\subsection{Gefäßkatheterassoziierte Infektionen}

Ein großer Teil der stationären Patienten erhält eine Infusionstherapie, und intravasale Katheter stellen einen Risikofaktor für die nosokomiale Sepsis dar. Die Hautflora an der Einstichstelle ist das primäre Erregerreservoir für die Kolonisierung des intravasalen Katheters. Koagulasenegative Staphylokokken sind daher vor Staph. aureus die häufigsten Erreger von katheterassoziierten Infektionen. Es kommen jedoch auch gramnegative Stäbchen und Enterokokken vor. Bei gramnegativen Stäbchen muss auch an kontaminierte Infusionslösungen gedacht werden. Das Risiko einer Katheterinfektion ist außer von der Liegedauer des Katheters vor allem auch von der Schwere der Grundkrankheit abhängig.

Zur Prävention von venenkatheterassoziierten Septikämien ist eine korrekte Hautantisepsis vor Anlage des Katheters mit einem alkoholhaltigen Kombinationspräparat, z. B. Isopropanol/Octenidin oder Isopropanol/Chlorhexidin mit einer Einwirkzeit von 1 min wichtig. Zum Legen des zentralen Venenkatheters sollten ein Mundschutz, ein steriler Kittel und sterile Handschuhe, sowie eine Haube, getragen werden. Die Haut um die Einstichstelle sollte mit einem großen sterilen Tuch abgedeckt werden. Die Infusionssysteme sollten nicht häufiger als alle 96 Stunden gewechselt werden. Parenterale Ernährungslösungen sollten innerhalb von 24 Stunden, reine Lipidlösungen nach Möglichkeit innerhalb von 12 Stunden infundiert werden. Hier sollten auch die Infusionssysteme nach dieser Zeit gewechselt werden. Infusionssysteme, über die Blut und Blutkomponenten verabreicht werden, sind nach einer Richtlinie der Bundesärztekammer nach 6 Stunden zu wechseln.

Bei peripheren Venenkathetern gibt es ebenso wie bei den zentralen Venenkathetern kein festes Wechselintervall. Vielmehr sollten eine tägliche Kontrolle der Indikation und der Kathetereintrittsstelle (am besten durch einen semipermeablen Folienverband hindurch) erfolgen und der Katheter bei Zeichen einer Phlebitis entfernt werden.

Bei Kindern, die über einen Zeitraum von mehr als 28 Tage auf einen sicheren venösen Zugang angewiesen sind, stehen getunnelte Broviac/Hickman-Katheter mit subkutanem Cuff oder vollständig subkutan implantierte PortKatheter zur Verfügung. Die Gesellschaft für Pädiatrische Onkologie und Hämatologie veröffentlicht regelmäßig aktualisierte evidenzbasierte Empfehlungen zur Infektionsprävention beim Einsatz solcher Langzeitkatheter.
Für Nabelgefäßkatheter bei Neugeborenen wird empfohlen, nach einer Liegedauer von 5-7 Tagen auf einen peripher angelegten zentralen Venenkatheter (PICC) zu wechseln, wenn dieser voraussichtlich noch über einen längeren Zeitraum erforderlich ist (Kat. II). Grundsätzlich gilt für alle Katheter, dass sie so kurz wie möglich liegen sollten. Die regelmäßige antiseptische Behandlung des Nabelrestes ohne Zeichen einer Omphalitis ist nur nötig, wenn ein Nabelvenenoder -arterienkatheter liegt.

\subsection{Infektionen des Gastrointestinaltrakts}

Bei nosokomialen Ausbrüchen gastrointestinaler Infektionen sind Viren die vorherrschenden Erreger. Außer Rota- und Noroviren gibt es zahlreiche weitere, die eine Gastroenteritis auslösen können. Diese Erreger werden überwiegend fäkaloral übertragen.

\section{Rotaviren}

Rotaviren werden darüber hinaus auch respiratorisch durch Ausscheidung des Erregers über Sekrete der Atemwege übertragen. Auch bei Einhaltung korrekter Hygienemaßnahmen sind nosokomiale Übertragungen in Zeiten erhöhter Prävalenz von Infektionen mit Rotaviren in der Bevölkerung oft nicht vollständig zu verhindern. Dies liegt daran, dass Kinder, die wegen anderer Krankheiten aufgenommen wurden, unerkannt Rotaviren ausscheiden können. Ausreichende Isolierungsmaßnahmen sind oft nicht durchführbar, da die Virusausscheidung schon in der Inkubationszeit von 1-3 Tagen beginnt und bis zu 8 Tage, je nach Immunstatus in Einzelfällen bis zu 30 Tage anhalten kann. Eine große Rolle bei der Übertragung spielen kontaminierte Flächen oder Gegenstände bzw. die Hände des Personals. Rotaviren können für mehrere Stunden auf Flächen überleben. Stationär behandelte Früh- und Neugeborene können mit einer der beiden zugelassenen oralen attenuierten Lebendvakzinen gegen Rotaviren geimpft werden. Zur Vermeidung der Übertragung von Impfviren sollte in diesen Fällen das Wechseln der Windel mit Kittel und Handschuhen erfolgen. Eine Isolierung der Patienten im Einzelzimmer ist wünschenswert, aber nicht zwingend notwendig.

\section{Noroviren}

Noroviren können außer über den fäkal-oralen Weg auch beim Erbrechen durch virushaltige Aerosole übertragen werden. Durch das typischerweise plötzlich auftretende Erbrechen kann der Erreger sich über die Aerosolbildung über mehrere Meter ausbreiten. Beim Umgang mit Erkrankten wird deshalb das Tragen eines Mund-Nasen-Schutzes empfohlen. Die Infektiosität ist sehr hoch, schon 10-100 Viruspartikel sind ausreichend, um eine Infektion hervorzurufen. Die Ansteckungsfähigkeit kann schon vor dem Auftreten 
erster Symptome bestehen und der Erreger ist noch mindestens 2 Tage nach Sistieren der Symptome, teilweise auch noch über mehrere Wochen (Cave! Immunsupprimierte) im Stuhl nachweisbar. In Bereichen mit immunsupprimierten Patienten werden die Patienten daher oft für die Dauer des stationären Aufenthaltes isoliert oder die Isolierung wird erst dann aufgehoben, wenn das Virus mit einer PCR-basierten Methode im Stuhl nicht mehr nachweisbar ist.

Antigenteste weisen eine deutlich geringere Sensitivität und Spezifität auf, Pseudoausbrüche durch falsch-positive Antigenteste sind beschrieben. Die Methode der Wahl zum Nachweis von Noroviren ist daher die PCR aus dem Stuhl.

Nach durchgemachter Infektion hält die Immunität nicht sehr lange an und ist außerdem nur gegen einen Genotyp gerichtet. Eine Infektion mit einem anderen Genotyp ist möglich. Typischerweise sind bei Ausbrüchen mit Noroviren in Kliniken nicht nur die Patienten, sondern auch das Personal betroffen. Zur Unterbrechung der Infektketten müssen betroffene Mitarbeiter konsequent zu Hause bleiben (mindestens 2 Tage nach Sistieren der Symptomatik).

Das zur Händedesinfektion eingesetzte Präparat muss gegen Noroviren wirksam sein (,,begrenzt viruzid plus“). Gleiches gilt für die Flächendesinfektion (besonders geeignet: Sauerstoffabspalter).

Zusätzlich können Handschuhe die Kontamination der Hände in Grenzen halten.

\section{Nahrungsmittelassoziierte Infektionen}

Bei solchen nosokomialen Infektionen findet man am häufigsten enteropathogene Bakterien wie Salmonellen, Campylobacter, darmpathogene Escherichia coli (z. B. enterohämorrhagische Escherichia coli, EHEC) und Enterotoxinbildende Staph. aureus, seltener auch Viren. Hier muss nach einer gemeinsamen (Risiko)-Lebensmittelquelle geforscht werden.

Die wichtigste krankenhaushygienische Maßnahme ist wiederum die Händedesinfektion. Durch die Einhaltung der Basishygienemaßnahmen können auch die meisten gastrointestinalen Infektionsübertragungen verhindert werden. Die Benutzung von Handschuhen bei möglichem Kontakt mit Stuhl bzw. der Genitalregion (Windelwechsel, Fiebermessen, Hautpflege) ist selbstverständlich. Über die Basishygienemaßnahmen hinausgehende Maßnahmen wie Kittelpflege sind bei Risiko einer Kontamination der Kleidung mit Stuhl erforderlich. Asymptomatische Patienten, die im gleichen Zimmer wie die an Durchfall erkrankten Patienten untergebracht sind, sollten in Bezug auf Hygienemaßnahmen wie diese behandelt werden. Bei Bedarf benötigen die Patienten eine eigene Toilette, gegebenenfalls einen patientenbezogenen Toilettenstuhl. Patienten, die im Rahmen von Ausbrüchen an einer Infektion durch den gleichen Erreger erkranken, können als Kohorte gemeinsam isoliert werden.
Da eine Durchfallerkrankung auch durch Personal übertragen werden kann, müssen symptomatische Mitarbeiter bis zur Genesung von der Patientenversorgung ausgeschlossen werden.

\subsection{Harnwegsinfektionen}

Auf pädiatrischen Intensivstationen treten in deutschen Kliniken, die an KISS teilnehmen, durchschnittlich 1-2 Harnwegsinfektionen pro 1000 Blasenkathetertagen auf. In einem Drittel der Fälle findet man bei diesen Patienten neurologische Erkrankungen, gefolgt von renalen und onkologischen Grundkrankheiten. Frühgeborene sind ebenfalls gefährdet. $50 \%$ der Kinder mit einer nosokomialen Harnwegsinfektion haben einen Blasenkatheter. Strenge Indikationsstellung, aseptisches Vorgehen bei der Anlage des HWK (Tab. 1, Schleimhautantiseptika), ausschließliche Verwendung geschlossener Systeme zur Harnableitung und möglichst zeitnahe Entfernung, sobald der HWK nicht mehr aus medizinischen Gründen benötigt wird, sind wichtige Bestandteile des Präventionsbündels.

\subsection{Infektionen der Haut und der Weichteile}

Auch bei Kindern kommen postoperative Wundinfektionen vor, die es durch eine sorgfältige Basishygiene, eine gezielte perioperative Antibiotikaprophylaxe (in der Regel lediglich eine Gabe 30-60 min vor der Operation, nur bei bestehender Indikation), durch die präoperative Antisepsis des OP-Gebietes und eine aseptische postoperative Wundpflege $\mathrm{zu}$ verhindern gilt. Hautinfektionen verursachen etwa $10 \%$ der nosokomialen Infektionen, am häufigsten sind sie auf Neugeborenenintensivstationen. Sie können sich als Infektionen der Eintrittsstelle von intravasalen Kathetern, Impetigo, Soor, Erysipel, Zellulitis, Phlegmone oder nekrotisierende Fasziitis manifestieren.

\subsection{ZNS-Infektionen}

Das Erregerspektrum der nosokomialen Meningitis unterscheidet sich von dem der ambulant erworbenen: Die häufigsten Erreger bei Kindern über 3 Monaten sind Koagulase-negative Staphylokokken und Staph. aureus, sehr viel seltener finden sich Enterokokken und gramnegative Stäbchen, noch seltener Propionibakterien. Bei der Staphylokokken-Meningitis ist meist ein chirurgischer Eingriff oder ein Trauma vorangegangen.

Die Übertragung von Meningokokken und Haemophilus influenzae erfolgt über respiratorische Tröpfchen und kann auch im Krankenhaus stattfinden. 
Bei Kindern mit Meningitis durch Neisseria meningitidis (Meningokokken) oder Haemophilus influenzae muss in den ersten 24 Stunden nach Beginn einer antibiotischen Behandlung eine respiratorische Isolierung (Kontakt und Tröpfcheninfektion; Abschn. 4.2) erfolgen. Nach jedem Kontakt mit potenziell infektiösen Sekreten (z. B. Speichel) müssen die Hände desinfiziert werden. Bei pflegerischem Kontakt ist ein Mund-Nasen-Schutz erforderlich. Bei der viralen Meningitis (häufigste Erreger sind Enteroviren) kann der Stuhl infektiös sein, sodass bei möglicher Kontamination der Kleidung Schutzkittel erforderlich sind.

\subsection{Varicella-Zoster-Virus}

Das Varicella-Zoster-Virus (VZV) ist auf den Schleimhäuten der Patienten sowie in den frischen Hautläsionen der Windpocken und in frischen Hauteffloreszenzen eines Zosters in hohen Konzentrationen nachweisbar. Varizellen sind bereits 2 Tage vor Auftreten des Exanthems ansteckend. Auch aerogene Übertragungen durch Tröpfchenkerne sind möglich, Abschn. 2.7. Die Infektion mit Windpocken kann für Neugeborene nichtimmuner Mütter, wenn sie unter der Geburt von der Mutter übertragen wird, und für immunsupprimierte Patienten lebensbedrohlich sein (Kap. \,Herpesvirus-Infektionen bei Kindern und Jugendlichen").

Nur Mitarbeiter mit ausreichenden Antikörpertitern gegen VZV (Impfung oder sicher durchgemachte Infektion) dürfen bei der Betreuung von VZV-infizierten Patienten eingesetzt werden. Bei fraglicher Windpockenanamnese und gleichzeitigem Fehlen eines Impfschutzes sollten Antikörpertiter bestimmt und bei Bedarf geimpft werden. Seronegativen Mitarbeitern, die Varizellen-exponiert sind, sollte eine Impfung angeboten werden und sie sollten bis 21 Tage nach der Exposition nicht in der direkten Patientenversorgung tätig sein. Personal mit Windpocken sollte erst dann, wenn keine neuen Läsionen mehr auftreten und alle verbliebenen Effloreszenzen verkrustet sind, wieder Patienten versorgen. Das Gleiche gilt für medizinisches Personal mit Herpes zoster. Nach der Neuformulierung des IfSG $\S 23$ ist der Arbeitgeber in der Pflicht, für die Infektionsprävention essenzielle Informationen zum Impfschutz der Mitarbeiter einzuholen.

Bei Patienten mit Windpocken oder Herpes zoster sowie bei immunsupprimierten Patienten mit lokalisiertem Zoster ist eine Isolierung nötig, um eine Übertragung durch direkten Kontakt wie auch eine aerogene Übertragung zu verhindern. Personen ohne Impfschutz oder Immunität nach durchgemachter Infektion sollen das Zimmer nicht betreten. Neugeborene von Müttern mit floriden Windpocken, die 5 Tage vor bis 2 Tage nach der Geburt manifest werden, sind in hohem Maße gefährdet, weil sie keine mütterlichen Antikörper haben. Sie werden passiv mit Hyperimmunglobulin und mit Aciclovir behandelt.

\section{Nosokomiale Infektionen bei Neugeborenen}

Fortschritte in der Neugeborenen-Intensivmedizin haben das Überleben von immer kleineren und auch kränkeren Frühgeborenen etwa ab der 24. Schwangerschaftswoche ermöglicht. Invasive Maßnahmen aller Art und patienteneigene Risikofaktoren, wie z. B. die extreme Unreife der Haut und der fehlende Nestschutz durch mütterliche Antikörper, führen aber zu einem erhöhten Risiko für nosokomiale Infektionen. Für den deutschsprachigen Raum sind die 2007 veröffentlichten, ausführlichen Empfehlungen der Kommission für Krankenhaushygiene und Infektionsprävention zur Prävention nosokomialer Infektionen bei neonatologischen Intensivpflegepatienten mit einem Geburtsgewicht unter $1500 \mathrm{~g}$ von besonderer Bedeutung.

Der in einigen Zentren berichtete zunehmende Nachweis von multiresistenten Erregern bei neonatologischen Patienten ist eine große Herausforderung, zumal hier unter intensivmedizinischen Bedingungen auch den Eltern eine aktive Rolle bei der Betreuung der Patienten zukommt. Wichtig ist, dass für alle Beteiligten verständliche, klare Hygieneregeln aufgestellt werden ohne dabei unbegründete einschneidende Isolierungsmaßnahmen in der Routine verbindlich zu machen.

\section{Definition}

Infektionen ab dem 4. Lebenstag, die nach mehr als 72 Stunden nach der Geburt manifest werden, gelten als nosokomial, es sei denn, eine Infektion vor diesem Zeitpunkt ist eindeutig nosokomial bedingt bzw. eine später auftretende Infektion ist wahrscheinlich perinatal übertragen worden. Ob der Erreger aus dem Mikrobiom der Mutter (intrapartale Infektion) oder aus einem exogenen Reservoir im Krankenhaus (postpartale Infektion) stammt, ist für die Definition einer nosokomialen Infektion nicht relevant.

Die häufigsten Krankenhausinfektionen bei Kindern auf neonatologischen Intensivstationen sind ebenso wie bei Erwachsenen Infektionen des Respirationstrakts, gefolgt von Harnwegsinfektionen und Sepsis.

In Deutschland werden im Rahmen des bundesweiten Krankenhaus-Infektions-Surveillance-Systems (KISS) im Modul NEO-KISS nosokomiale Septikämien, Pneumonien und die nekrotisierende Enterokolitis (NEC) auf neonatologischen Intensivstaionen (NICU) bei Kindern mit einem Geburtsgewicht von 500-1499 g erfasst. Definitionen und aktuelle Daten sind über http://www.nrz-hygiene.de/surveil lance/kiss/neo-kiss/ verfügbar. 


\section{Ätiopathogenese}

Die Erreger nosokomialer Infektionen stammen sehr häufig aus der endogenen Flora des Patienten, können aber auch von anderen Patienten, von Besuchern, vom Personal oder seltener aus der Umgebung übertragen werden. Eine Besonderheit der frühgeborenen Patienten ist, dass sie kurz nach der Geburt mit Bakterien aus der Krankenhausumgebung besiedelt werden.

Bei venenkatheterassoziierten Septikämien werden am häufigsten koagulasenegative Staphylokokken, gefolgt von Enterokokken und Staph. aureus isoliert. Nosokomiale Pneumonien werden am häufigsten durch Pseudomonas aeruginosa verursacht. Häufigste Erreger von Harnwegsinfektionen sind Escherichia coli, Enterokokken, Enterobacter und Pseudomonas spp. Ein Fünftel der postoperativen Infektionen im Operationsgebiet werden durch Staph. aureus verursacht. In Ausbruchssituationen wurden zudem unter anderem ESBLbildende Klebsiella pneumoniae (2 MRGN NeoPäd), ESBLbildende Escherichia coli, Serratia marcescens und MRSA beschrieben.

Rota-, Noro- und Adenoviren sind die häufigsten Erreger gastrointestinaler Infektionen bei Frühgeborenen. Während der Wintermonate können respiratorische Viren, vor allem RSV, nosokomiale Infektionsausbrüche auf NICUs verursachen. Auch passiv mit Palivizumab immunisierte Kinder können an einer RSV-Infektion der oberen Atemwege erkranken.

Risikofaktoren Jede invasive Maßnahme, die die natürliche Infektionsbarriere durchbricht, erhöht das Infektionsrisiko beim Neugeborenen in noch stärkerem Maße als beim Erwachsenen. Schon Kopfhautelektroden können Eintrittspforten für Erreger aus dem mütterlichen Genitaltrakt sein. Unreife und/oder kranke Neugeborene müssen häufig über eine Sonde ernährt werden. Daraus kann eine Kolonisation des oberen Gastrointestinaltrakts mit Mikroorganismen aus der Umgebung resultieren. Wenn Muttermilch oder Flüssignahrung über mehrere Stunden bei Raumtemperatur infundiert werden, bekommen Mikroorganismen die Möglichkeit, sich im Schlauch oder im Reservoir zu vermehren. Mit zunehmender Kolonisation der Nahrung steigt das Risiko einer Sepsis oder einer nekrotisierenden Enterokolitis (NEC). Bei der Verabreichung von Muttermilch oder Formulanahrung über eine Sonde wird zusätzlich zur hygienischen Händedesinfektion das Tragen von Einmalhandschuhen empfohlen. Das Ablegen der Sondierungsspritzen zum Aufwärmen im Inkubator ist wegen des Kontaminationsrisikos nicht zu empfehlen.

Unnötig lange Antibiotikatherapien bei Infektionsverdacht nach der Geburt erhöhen außerdem das Risiko der NEC und von Candida-Infektionen, insbesondere, wenn hier Cephalosporine der Gruppe 3 zum Einsatz kommen.
Auf intravasale Katheter wird unter Abschn. 7.2 eingegangen.

Kolonisation Die erste Exposition des Kindes gegenüber der mütterlichen Flora erfolgt normalerweise nach dem Blasensprung und während der Passage durch den Geburtskanal. Nach Kaiserschnittentbindung verzögert sich die mikrobielle Kolonisation. Postnatal werden Mikroorganismen auch von anderen Familienangehörigen, Krankenhauspersonal und aus der unbelebten Umgebung übertragen. Bei gesunden Neugeborenen dominieren grampositive Bakterien im Pharynx und koagulasenegative Staphylokokken im Nabelbereich. Anaerobier (bei gestillten Kindern vor allem Lactobazillen) und Escherichia coli besiedeln primär den Darm. Die Kolonisation eines Kindes auf einer Intensivstation verläuft unterschiedlich und wird beim Einsatz von Breitspektrum-Antibiotika zum Teil massiv verändert. Klebsiellen, Enterobacter und Citrobacter-Spezies kommen häufig im Stuhl oder am Nabel vor. Koagulasenegative Staphylokokken aus der Krankenhausumgebung (häufig mit Methicillin-Resistenz) besiedeln Haut und Schleimhäute von Frühgeborenen. Pädiatrische Patienten erwerben wie Erwachsene Infektionen im Zusammenhang mit intravasalen Kathetern primär aus dem Reservoir ihrer Hautflora.

Es konnte gezeigt werden, dass Infektionsraten bei Personalmangel und bei Überbelegung der Station ansteigen. Darüber hinaus treten auf einer NICU immer wieder Notfallsituationen auf, bei denen oft kaum genügend Zeit für eine Händedesinfektion besteht. Dann sollten zumindest Einmalhandschuhe vor Berühren des Kindes angezogen werden.

\section{Mikrobiologische Diagnostik}

Bei begründetem Infektionsverdacht ist zumindest eine aerobe Blutkultur, mit einem Volumen möglichst von $1 \mathrm{ml}$ abzunehmen (aerobe Paeds Flasche 1-3 ml). Anaerobe Blutkulturen werden nur bei bestimmten klinischen Situationen gefordert, z. B. Verdacht auf NEC. Die Spitzen von bei Infektionsverdacht entfernten zentralen Venenkathetern sollten mit einer semiquantiativen Methode mikrobiologisch untersucht werden. Ein mikrobiologisches Screening (z. B. wöchentliche Nasen-, Rachen- und Analabstriche) kann dazu beitragen, nosokomiale Übertragungen frühzeitig zu erkennen. Zudem können die Ergebnisse dieses Screenings bei der Auswahl einer kalkulierten Antibiotikatherapie bei Verdacht auf eine LOS (Late-onset-Sepsis) hilfreich sein.

Über ein Personalscreening bei Verdacht auf nosokomiale Übertragungen von MRSA sollte in Absprache mit der Krankenhaushygiene und dem Betriebsarzt entschieden werden, wenn andere Maßnahmen der Eindämmung nicht ausreichen und ein Zusammenhang mit Personal begründet vermutet wird. Bei Transmissionen/Ausbrüchen von MRGN stellen 
besiedelte Mitarbeiter von vorneherein kein realistisches Reservoir dar.

Klinische Isolate mit Multiresistenz sollten bei Ausbruchsverdacht für eine gegebenenfalls spätere molekularbiologische Typisierung vom Labor asserviert werden: Isolate aus Blut oder Liquor für 6 Monate.

\section{Therapie}

In NICUs sollte es schriftlich formulierte Standards für die Diagnostik und Therapie der EOS (Early-onset-Sepsis) und der LOS geben, in denen die Antinfektiva der 1. Wahl mit Dosierungsangaben je nach Gestationsalter (und postpartalem Alter) festgelegt sind. Diese Standards sollten insbesondere auch Indikationen für Reserveantibiotika (z. B. Vancomycin, Meropenem) definieren. Bei sehr unreifen Frühgeborenen ist es durchaus zulässig, bei begründetem Verdacht auf eine LOS sehr zeitnah eine kalkulierte Antibiotikatherapie zu beginnen. Diese sollte jedoch bei günstigem klinischen Verlauf, negativen Blutkulturen und ausbleibendem Anstieg der Entzündungsparameter nach 48 Stunden wieder beendet werden (AWMF-Leitlinie Register Nr. 024/008 Entwicklungsstufe: S2k: Bakterielle Infektionen bei Neugeborenen). Die abteilungsspezifische Erreger- und Resistenzstatistik sollte jährlich beurteilt und zur Anpassung der empirischen Therapievorgaben verwendet werden.

\section{Prävention}

In der neonatologischen Intensivpflege müssen gelegentlich spezielle Hygienemaßnahmen ergriffen werden. Spezielle Aspekte zu multiresistenten Erregern werden in Tab. 3 und Abschn. 4.4 genannt.

Die Hygienemaßnahmen beim Umgang mit z. B. intravasalen Kathetern oder zur Pneumonieprävention folgen den gleichen Prinzipien wie bei älteren Kindern. Lediglich einige Aspekte wie die spezielle Hautantisepsis, der Verzicht auf „needle free connectors“ (NFC) und auf Isopropanol freisetzende Verschlusskappen im Inkubator unterscheiden sich hier.

Direkt erreichbare Händedesinfektionsmittelspender müssen in jedem Zimmer verfügbar sein. Die Bedeutung der Händehygiene zur Infektionskontrolle steht an erster Stelle.

Auf NICUs sind oft deutlich mehr als 2 Inkubatoren in einem Behandlungszimmer untergebracht, die baulichen Voraussetzungen erschweren oft eine erregerspezifische Isolierung oder Kohortierung. Andererseits ist bei ausreichendem Abstand zwischen den Inkubatoren (mindestens $2 \mathrm{~m}$ ) auch eine effektive Kontaktisolierung am Behandlungsplatz möglich. Inkubatoren sind jedoch per se keine „Isolierzimmer“" Der Behandlungsplatz mit allen Monitoren und Infusionsgeräten sowie gegebenenfalls auch der Liege für das Känguruhing befinden sich innerhalb der Isolierungsgrenze.

Im Ergebnis muss auf der jeweiligen NICU interdisziplinär ein Isolierungskonzept erarbeitet werden, das nicht nur der krankenhaushygienischen Risikokategorie des jeweiligen
Erregers, sondern auch dem intensivmedizinischen Betreuungsaufwand bei begrenzten Personalressourcen gerecht wird. So kann es sinnvoll sein, ein mit MRSA besiedeltes Kind mit geringem Betreuungsaufwand im Mehrbettzimmer mit Kontaktisolierung am Bettplatz zu betreuen und gleichzeitig ein schwer krankes Kind ohne besonderen Erregernachweis mit optimalen Möglichkeiten im Einzelzimmer zu versorgen.

Oberste Priorität für eine räumliche Distanzierung haben Patienten mit 4MRGN-Besiedlung/Infektion oder leicht übertragbaren Virusinfektionen. Auch ohne Vorliegen von besonderen Resistenzen sind manche Erreger tendenziell häufiger mit Infektionen assoziiert (Serratia marcescens, Pseudomonas aeruginosa, Enterobacter spp.) und oder häufiger bei Ausbrüchen (Klebsiella pneumoniae, Acinetobacter baumannii). Hier sollte bei Nachweis bei mehreren Kindern eher an zusätzliche Maßnahmen wie Kohortierung und Feintypisierung gedacht werden als beispielsweise bei Enterokokken.

In die abteilungsspezifische Risikoanalyse fließen auch lokale Besonderheiten wie regionale Resistenzsituation und Erfahrungen mit stattgehabten Ausbrüchen (schon bekannte Klone, bei Wiederauftreten zügige Typisierung)

Haut- und Nabelpflege Weil die Kolonisierung Neugeborener am Nabel beginnt und erst von dort der übrige Körper besiedelt wird, kommt der Nabelpflege eine besondere Bedeutung zu. Sofern der Nabelstumpf nicht verunreinigt ist oder als Zugang für intravaskuläre Katheter genutzt wird, ist eine Antiseptik nicht erforderlich. Der Nabelstumpf wird nicht als Wunde angesehen, stellt aber eine potenzielle Eintrittspforte für Sekundärinfektionen dar. Bei lokalen Entzündungszeichen ist daher ein Antiseptikum (z. B. Octenidin) indiziert. Auf keinen Fall sollten quecksilberhaltige Antiseptika verwendet werden, weil sie toxikologisch und allergologisch bedenklich und zudem antimikrobiell nicht ausreichend wirksam sind. Auch alkoholhaltige Präparate sollten nur mit Vorsicht angewendet werden, weil sie die Haut reizen bzw. resorbiert werden können. Bei schmierig belegtem Nabelschnurstumpf sollte ein Abstrich mikrobiologisch untersucht werden. Sobald der Nabelschnurstumpf trocken und reizlos aussieht, ist eine besondere Behandlung nicht mehr erforderlich.

Die Haut des Neugeborenen sollte möglichst wenig durch Austrocknung, irritierende Substanzen oder mechanische Belastung traumatisiert werden.

Die Frage der am besten geeigneten Hautantisepsis vor invasiven Maßnahmen (z. B. Anlage eines PICC oder eines PVK) bei intensivmedizinischen Frühgeborenen ist ungeklärt: Alkohole können verbrühungsähnliche Hautschäden auslösen. Die KRINKO empfiehlt in den ersten Lebenswochen Octenidin $0,1 \%$ ohne Alkoholzusatz (muss in der Apotheke zubereitet und portioniert werden), danach gege- 
benenfalls auch Octenidin $0,1 \%$ plus Phenoxyethanol (Fertigpräparat). PVP-jodhaltige Antiseptika sind kontraindiziert. Auch vor der Anlage eines Blasenkatheters kann eine Antisepsis mit Octenidin 0,1\% erfolgen. Grundsätzlich (auch beim Octenidin!) soll vermieden werden, dass größere Mengen des Antiseptikums außerhalb des eigentlich zu desinfizierenden Hautareals verbleiben (Abdeckung!).

Nosokomiale Konjunktivitis Die Augen werden dabei am häufigsten mit gramnegativen Erregern aus respiratorischen Sekreten infiziert. Daher muss man vermeiden, dass beim endotrachealen oder pharyngealen Absaugen Sekret in die Augen gelangt (mit einem sauberen Tupfer abdecken)

Ernährung Frühgeborene sollen möglichst mit frischer Muttermilch ernährt werden. Diese ist gerade für Frühgeborene und kranke Kinder wegen ihrer ausgewogenen Nährstoffzusammensetzung, ihrer immunologisch wirksamen Inhaltsstoffe, den antiinfektiösen Bestandteilen sowie dem Gehalt an Hormonen und Wachstumsfaktoren besonders wertvoll. Auch die Ernährung mittels gespendeter Frauenmilch ist in vielen Einrichtungen etabliert und wird nach Möglichkeit einer Ernährung mit Formulanahrung vorgezogen. Ziel ist es, Muttermilch unbehandelt und zügig zu verabreichen.

\section{Hygienemaßnahmen}

- Zum Auffangen der Milch sollten nur desinfizierte oder autoklavierte Gefäße verwendet werden. Eine sichere Erwärmung von Milchflaschen erfolgt z. B. durch wasserfreie Flaschenwärmer. Das Anwärmen im Wasserbad ist obsolet, weil dieses ein potenzielles Erregerreservoir für gramnegative Erreger darstellt.

- Im Rahmen des stationären Aufenthaltes der Mutter werden die erforderlichen Hilfsmittel durch die Einrichtung zur Verfügung gestellt und nach Anleitung entsprechend den Hygienestandards der Einrichtung gehandhabt (Elterninformation, Einhaltung der Kühlkette).

- Sowohl eine (thermische) Aufbereitung der Hilfsmittel (z. B. Abpumpsets, Milchflaschen etc.) als auch eine Verwendung von Einmalmaterial ist aus hygienischer Sicht sicher möglich.

- Vor dem Richten und Anlegen des Abpumpsets sollte in klinischer Umgebung eine Händedesinfektion durchgeführt werden. Im privaten Umfeld ist gründliches Händewaschen ausreichend.

- Wird zu Hause abgepumpt, sollen die Eltern auch schriftliche Informationen zum Umgang mit der gewonnenen Muttermilch enthalten.

- Bei Lagerung und Transport der Milch ist ebenfalls auf die Einhaltung der Kühlkette (ca. 4-6 ${ }^{\circ} \mathrm{C}$ ) zu achten. Deutlich übertemperierte Milch sollte durch das Personal verworfen werden.

- Die Reinigung der mit der Muttermilch in Kontakt kommenden Teile der Hilfsmittel erfolgt im privaten Umfeld in der Regel mit heißem Wasser und Spülmittel (thermische „Desinfektion“, z. B. mittels Geschirrspülmaschine auf höchster Stufe oder Auskochen) unter Berücksichtigung der Herstellerangaben.

Mikrobiologische Anforderungen Bakteriologische Untersuchungen müssen bei reifen Neugeborenen und Frühgeborenen ohne besonderes Risikoprofil außerhalb spezifischer Indikationen, wie z. B. bei Mastitis, Sepsis, Verdacht auf NEC, Nahrungsmittelunverträglichkeit des Kindes etc. nicht durchgeführt werden. Empirisch etabliert erfolgen sie lediglich bei hohem kindlichem Risikoprofil unter Berücksichtigung unter anderem von Frühgeburtlichkeit, aktuellem Gewicht, Geburtsgewicht und Immunstatus. Richtwerte für Keimzahlgrenzen werden häufig herangezogen, sind jedoch hinsichtlich ihrer infektiologischen Relevanz nicht gut belegt.

Richtwerte für tolerable Keimzahlen in $1 \mathrm{ml}$ Muttermilch bei Risikokindern*

- Möglichst keine gramnegativen Bakterien

- Je nach Risikoprofil keine oder maximal $100 \mathrm{KBE} /$ $\mathrm{ml}$ Staph. aureus oder $\beta$-hämolysierende Streptokokken

- Gesamtkeimzahl $<=10^{4} \mathrm{KBE} / \mathrm{ml}$

*Bei sehr kleinen Frühgeborenen CMV-Status der Mutter beachten, Pasteurisierung erwägen

Formulanahrung muss in der Milchküche des Krankenhauses unter einwandfreien hygienischen Bedingungen zubereitet werden. Dabei ist zu beachten, dass die Pulvernahrung selbst meist nicht steril ist. Geringe Keimzahlen aerober Sporenbildner sind dabei unproblematisch. Pathogene Erreger, wie beispielsweise Enterobakterien (z. B. Enterobacter sakazakii) können dagegen zu Infektionen führen, insbesondere dann, wenn die Nahrung nach der Zubereitung nicht umgehend gekühlt bzw. zu lange gelagert wird (Herstellerangaben beachten).

Besucher Eltern sollten sich vor Betreten der Intensivstation die Hände und gegebenenfalls auch die Unterarme desinfizieren (Anleitung durch Pflegepersonal). Sie können dann in ihrer (sauberen) Privatkleidung zu ihrem Kind gehen. Im Sinne des Konzeptes, eine mikrobielle Besiedlung durch mütterliche Hautflora gegenüber einer aus der Stationsumge- 
bung stammenden zu fördern, wird in einigen NICUs auf einen Schutzkittel für die Mutter/Eltern bewusst verzichtet. Muss das Kind im Inkubator bleiben, können die Eltern mit ihren zuvor desinfizierten Händen und Unterarmen durch die Öffnungen des Inkubators direkten Kontakt mit dem Kind aufnehmen. Man muss den Eltern erklären, dass sie außer mit dem eigenen Kind keinen direkten Kontakt mit anderen Mitpatienten haben dürfen und auf die eine effektive Händehygiene behindernden Faktoren wie Schmuck, Armbanduhren, gegebenenfalls künstliche Fingernägel hinweisen.

Wenn die Eltern z. B. eine respiratorische Infektion haben und den dringenden Wunsch äußern, ihr Kind zu besuchen, bevor die Infektion ausgeheilt ist, muss man ihnen die potenzielle Infektionsgefahr für ihr Kind und die besondere Bedeutung der Händehygiene und das Tragen des Mund-NasenSchutzes erklären. Liegt das Kind im Inkubator und darf nicht herausgenommen werden, sind außer der gründlichen Händedesinfektion und Mund-Nasen-Schutz keine weiteren Maßnahmen erforderlich. Man muss die Eltern auch darauf hinweisen, dass sie auf der Station möglichst wenig berühren sollen und sich nach jedem Niesen oder Naseputzen die Hände desinfizieren müssen. Eltern mit eitrigen Infektionen der Haut sollten die Intensivstation nicht betreten. Nur in Ausnahmefällen und bei sehr kleinen Infektionsherden, z. B. an den Händen, kann man zuverlässigen Eltern erlauben, die Intensivstation zu betreten, indem man sie beispielsweise über den gut schließenden Verband Einmalhandschuhe anziehen lässt. Eltern mit Herpes labialis müssen darauf hingewiesen werden, dass sie mit ihrem Kind nicht schmusen dürfen. Außerdem müssen auch sie einen Mund-NasenSchutz tragen, wenn sie das Kind auf dem Arm halten wollen.

Auch Geschwister können zu Besuchen auf Intensivstationen mitgenommen werden, im Gegensatz zu ihren Eltern allerdings mit der Einschränkung, dass sie keine Infektionen haben dürfen (Information auch durch Merkblatt). Die Eltern werden nach Symptomen, die auf eine Infektion hinweisen können, gefragt. Ebenfalls werden stattgehabte Kontakte mit einem an einer infektiösen (Kinder-)Krankheit erkrankten Kind eruiert (z. B. Windpocken ohne sichere Immunität). Außerdem muss sichergestellt sein, dass die Eltern gut auf das Geschwisterkind aufpassen und es in ihrer Nähe behalten. Dem Geschwisterkind müssen vor und nach dem Kontakt mit dem kranken Kind die Hände sorgfältig desinfiziert werden.

Schutzkittel Schutzkittel, die über der normalen Arbeitskleidung, also auf einer Intensivstation über der Bereichskleidung, getragen werden, sollten bei direktem Kontakt mit dem Kind (z. B. bei der Pflege außerhalb des Inkubators) verwendet werden (Abschn. 3). Das routinemäßige Anziehen eines Schutzkittels beim Betreten oder Verlassen der Intensivstation hat demgegenüber keinen infektionsprophylaktischen Effekt.
Bettwäsche, Kinderkleidung, Windeln Wäsche sollte mit einem validierten desinfizierenden Waschverfahren aufbereitet werden. Eine Sterilisation ist nicht erforderlich.

\section{Infektionsprophylaxe in Gemeinschaftseinrichtungen}

\subsection{Vorbemerkungen}

In Bezug auf die Infektionskontrolle unterscheiden sich Gemeinschaftseinrichtungen von Krankenhäusern, in einigen Punkten gibt es jedoch Gemeinsamkeiten:

- Je jünger die Kinder sind, desto infektionsanfälliger sind sie. Sie sind bei einfachen Aktivitäten, wie Essen und Trinken oder bei der persönlichen Hygiene auf Hilfe durch die Betreuungspersonen angewiesen, die Infektionen von Kind zu Kind übertragen können und ihrerseits selbst einem Infektionsrisiko ausgesetzt sind.

- Kinder neigen dazu, ihre Umgebung mit den Händen oder dem Mund zu erkunden. Dadurch entstehen vielfältige Verbreitungsmöglichkeiten von Körperflüssigkeiten wie Speichel, Nasensekret, Fäzes und Urin. Daher spielt die unbelebte Umgebung als Reservoir von Krankheitserregern eine größere Rolle. So konnten z. B. Rotaviren oder Cytomegalie-Viren bei Umgebungsuntersuchungen in Kindertagesstätten nachgewiesen werden.

\subsection{Ausschluss und Wiederzulassung erkrankter Kinder}

Eines der Probleme in Kindergärten und Kindertagesstätten ist die Festlegung geeigneter Kriterien für den krankheitsbedingten Ausschluss eines Kindes. Neben dem Schutz der noch gesunden Kinder muss auch berücksichtigt werden, dass oft ein Elternteil der ausgeschlossenen Kinder nicht arbeiten gehen kann und nicht unerhebliche Kosten entstehen, die die Allgemeinheit zu tragen hat. Die folgende Übersicht ist den Empfehlungen des Robert Koch-Instituts entnommen und soll Hilfestellung für den Ausschluss erkrankter bzw. infizierter Kinder und deren Wiederzulassung geben.

Dabei ist berücksichtigt, dass bei Kindern leichte Verläufe häufig sind und dass Infektionen oft schon vor dem Auftreten von Symptomen übertragen werden. Viele Kinder müssen daher nicht ausgeschlossen werden, wenn sie leichtgradige Infektionen des Respirations- oder des Gastrointestinaltrakts haben. Kinder mit schwerer Symptomatik hingegen sollten nach Hause geschickt werden. 
Empfehlungen für die Wiederzulassung in Schulen und sonstigen Gemeinschaftseinrichtungen

(nach den Empfehlungen des Robert Koch-Instituts und dem jeweilig aktuellen RKI Ratgeber für Ärzte: Empfehlungen, Erkrankungen nach $\S 34$ IfSG, Auswahl)

- Diphtherie: Ärztliche Bescheinigung notwendig, in der bestätigt wird, dass in 3 Abstrichen keine toxinbildenden Diphtheriebakterien mehr nachgewiesen wurden. Der 1. Abstrich ist frühestens 24 Stunden nach Absetzen der antibiotischen Therapie $\mathrm{zu}$ entnehmen.

- Enterohämorrhagische E. coli (EHEC): nach klinischer Genesung und dem Vorliegen von 3 aufeinanderfolgenden negativen Stuhlbefunden im Abstand von 1-2 Tagen. Ein schriftliches Attest ist erforderlich.

- Gastroenteritiden (bakteriell: Salmonellen, Campylobacter, Yersinia enterocolitica; viral: Rota-, Adeno- oder Noroviren): nach Abklingen des Durchfalls (geformter Stuhl) bzw. des Erbrechens (vor allem bei Noroviren). Ein schriftliches ärztliches Attest ist nicht erforderlich.

- Haemophilus-influenzae-Typ-b-Meningitis: nach antibiotischer Therapie und nach Abklingen der klinischen Symptome. Ein schriftliches ärztliches Attest ist nicht erforderlich.

- Impetigo contagiosa: 24 Stunden nach Beginn einer Antibiotikabehandlung, ansonsten nach klinischer Abheilung der befallenen Hautareale. Ein schriftliches ärztliches Attest ist nicht erforderlich.

- Lungentuberkulose, offene: Bei initialem mikroskopischem Nachweis von säurefesten Stäbchen sind mikroskopisch negative Befunde in 3 aufeinanderfolgenden Proben von Sputum, Bronchialsekret oder Magensaft erforderlich. Bestanden initial Fieber oder Husten, so ist eine 2 Wochen anhaltende Entfieberung oder Abklingen des Hustens abzuwarten. Nach einer lege artis durchgeführten antituberkulösen Kombinationstherapie von 3 Wochen Dauer können Gemeinschaftseinrichtungen wieder besucht werden, wenn die oben genannten Kriterien erfüllt sind. Ein schriftliches ärztliches Attest ist erforderlich.

- Masern: frühestens 5 Tage nach Exanthemausbruch, nach Abklingen der klinischen Symptome. Ein ärztliches Attest ist nicht erforderlich.

- Meningokokken-Infektion: 24 Stunden nach Beginn einer antibiotischen Therapie nach Abklingen der klinischen Symptome nach ärztlichem

(Fortsetzung)
Ermessen. Ein schriftliches ärztliches Attest ist nicht erforderlich.

- Pertussis (Keuchhusten): Frühestens 5 Tage nach Behandlungsbeginn, ohne Antbiotikatherapie bis 3 Wochen nach Erkrankungsbeginn. Ein schriftliches ärztliches Attest ist nicht erforderlich.

- Parotitis epidemica (Mumps): nach Abklingen der klinischen Symptome, frühestens 9 Tage nach Auftreten der Parotisschwellung.

- Pediculosis capitis (Kopflausbefall): direkt nach der ersten von 2 erforderlichen Behandlungen mit z. B. Permethrin, Pyrethrum, Allethrin. Als Nachweis zur Wiederzulassung reicht im Einvernehmen mit dem Gesundheitsamt eine Bestätigung der Eltern aus, dass eine sachgemäße Behandlung durchgeführt wurde. Falls die Weiterverbreitung von Kopfläusen in einer Gemeinschaftseinrichtung zu einem Problem wird, kann die Einrichtung jedoch ein ärztliches Attest zur Bestätigung der Lausfreiheit einfordern.

- Scabies (Krätze): nach Behandlung und klinischer Abheilung der befallenen Hautareale. Ein schriftliches ärztliches Attest ist erforderlich.

- Scharlach oder sonstige Streptococcus-pyogenesInfektionen: 24 Stunden nach Beginn einer wirksamen antibiotischen Behandlung und nach Abklingen der Krankheitssymptome. Ein schriftliches ärztliches Attest ist nicht erforderlich.

- Shigellose: Typhus abdominalis

- Typhus abdominalis/Parathyphus: nach klinischer Gesundung und 3 aufeinander folgenden negativen Stuhlproben im Abstand von 1-2 Tagen. Die 1. Stuhlprobe sollte frühestens 24 Stunden nach Ende einer Antibiotikatherapie erfolgen. Ein schriftliches ärztliches Attest ist erforderlich.

- Varizellen (Windpocken): Bei unkompliziertem Verlauf ist ein Ausschluss für 1 Woche aus der Gemeinschaftseinrichtung in der Regel ausreichend. Ein schriftliches ärztliches Attest ist nicht erforderlich.

- Virushepatitis A oder E: 2 Wochen nach Auftreten der ersten Symptome bzw. 1 Woche nach Auftreten des Ikterus. Ein schriftliches ärztliches Attest ist nicht erforderlich.

Anmerkungen: a§ 34 Abs. 1 Satz 3 des IfSG bestimmt, dass Kinder, die das 6 . Lebensjahr noch nicht vollendet haben und an infektiöser Gastroenteritis erkrankt oder dessen verdächtig sind, die Gemeinschaftseinrichtungen nicht besuchen dürfen, bis nach ärztlichem Urteil eine Weiterverbreitung der Erkrankung nicht mehr zu befürchten ist. 


\subsection{Personal}

Jede Betreuungsperson in Einrichtungen der Pädiatrie, in Gemeinschaftseinrichtungen für das Vorschulalter und Kinderheimen sollte vor Aufnahme ihrer Tätigkeit betriebsärztlich untersucht werden. Dabei sollte der Impfstatus erhoben werden. Gegen folgende Krankheiten sollte Immunität bestehen, entweder durch Impfung oder infolge durchgemachter Infektion: Tetanus, Diphtherie, Masern, Mumps, Röteln, Poliomyelitis (generelle Impfempfehlungen der Ständigen Impfkommission, STIKO). Zusätzlich werden nach den aktuellen Empfehlungen der STIKO folgende Impfungen für Personal in Kindertagesstätten, Kinderheimen, Gemeinschaftseinrichtungen für das Vorschulalter etc. vorgegeben: Hepatitis A, Hepatitis B, Pertussis und Varizellen. Auch eine jährliche Impfung gegen Influenza ist dringend zu empfehlen. Mit weiblichen Betreuungspersonen sollte das Risiko einer Infektion mit CMV, Parvovirus B19, Röteln und Varizellen im Falle einer Schwangerschaft besprochen werden.

\subsection{Einzelne Infektionen}

\section{Infektionen des oberen Respirationstrakts}

Kinder mit geringen Symptomen einer viralen Infektion des oberen Respirationstraktes wie Rhinitis, Husten, Pharyngitis oder Otitis media können in der Gemeinschaftseinrichtung weiter betreut werden. Ein Ausschluss dieser Kinder hat wahrscheinlich keinen wesentlichen Einfluss auf die Inzidenz dieser Krankheiten. Ein Ausschluss sollte jedoch dann erfolgen, wenn ein spezifischer Erreger nachgewiesen wird, der eine Isolierung nahelegt (z. B. A-Streptokokken, Übersicht „Empfehlungen für die Wiederzulassung in Schulen und sonstigen Gemeinschaftseinrichtungen"), oder das Kind in seinem Befinden derart eingeschränkt ist, dass es an den üblichen Aktivitäten nicht mehr teilnehmen kann.

\section{Haemophilus influenzae}

Übertragungen von Haemophilus influenzae Typ b sind zwischen ungeimpften Kindern leicht möglich (Kap. \ „Bakterielle Infektionen bei Kindern und Jugendlichen: gramnegative Stäbchen“). Jüngere Kinder sind empfänglicher in Bezug auf Ansteckung und Schwere des Verlaufs als ältere. Infektionsquelle kann auch ein asymptomatischer Träger sein. Bei Auftreten von invasiven Infektionen wie Epiglottitis, Sepsis oder Meningitis muss der Impfstatus aller exponierten Kinder erhoben werden. Nichtimmunisierte Kinder sollten geimpft werden. Die Impfung reduziert nicht nur zum Teil schwerwiegende Erkrankungen, sondern verhindert auch Übertragungen durch asymptomatische Träger. Beim Auftreten eines Falles in einem Kindergarten, in dem sich unzureichend geimpfte Kinder befinden, ist eine Postexpositionsprophy- laxe mit Rifampicin für exponierte (ungeimpfte) Kinder und deren (ungeimpfte) Betreuer (im Falle einer Schwangerschaft Ceftriaxon) zu erwägen. Dies gilt insbesondere dann, wenn auch Kinder unter 2 Jahren dort betreut werden. Liegt jedoch der Kontakt zum Indexpatienten mehr als 7 Tage zurück, ist eine Chemoprophylaxe nicht mehr sinnvoll.

\section{Meningokokken-Infektionen}

Bei Auftreten einer Meningokokken-Infektion (Kap. > „Bakterielle Infektionen bei Kindern und Jugendlichen: grampositive und gramnegative Kokken") sollten alle engen Kontaktpersonen eine Prophylaxe mit Ciprofloxacin (Erwachsene), Rifampicin (Kinder) oder Ceftriaxon (Schwangere) erhalten.

$\mathrm{Zu}$ Impfstoffen, Kap. \ „Impfungen und Reiseimpfungen bei Kindern und Jugendlichen“, Kap. \ „Bakterielle Infektionen bei Kindern und Jugendlichen: grampositive und gramnegative Kokken".

\section{Gastroenteritis}

$\mathrm{Zu}$ ausführlichen Erläuterungen zur Gastroenteritis, Abschn. 7.3; Kap. \ „Bakterielle Infektionen bei Kindern und Jugendlichen: gramnegative Stäbchen“, Kap. \ „Gastrointestinale Viren bei Kindern und Jugendlichen“.

\section{Hepatitis A}

Gemeinschaftseinrichtungen stellen eine mögliche Quelle für die Ausbreitung von Hepatitis A (Kap. \ „Hepatitis bei Kindern und Jugendlichen") dar. Symptomatische Krankheiten fallen in der Regel nicht bei den meist asymptomatischen Kindern, sondern bei ihren erwachsenen Kontaktpersonen auf. Ikterische Kinder sollten, wie oben bei der Diarrhö beschrieben, behandelt werden. Bei Krankheitsverdacht sollte eine IgM-Antikörpertestung erfolgen. Dies gilt auch für Personal und Haushaltskontakte.

Kontaktpersonen sind über Übertragungswege, Symptome und präventive Maßnahmen zu informieren. Eine Isolierung von Kontaktpersonen ist bei bestehendem Impfschutz oder nach früher durchgemachter Erkrankung nicht erforderlich. Nach einer postexpositionellen Schutzimpfung, die so früh wie möglich durchgeführt werden sollte, ist mit einem Impfschutz 1-2 Wochen nach Impfung zu rechnen. Ansonsten sind Kontaktpersonen 4 Wochen nach dem letzten Kontakt zu einer infektiösen Person vom Besuch von Schulen und anderen Gemeinschaftseinrichtungen auszuschließen, sofern nicht die strikte Einhaltung von hygienischen Maßnahmen zur Verhütung einer Übertragung gewährleistet ist.

Bis 2 Wochen nach Auftreten der ersten Symptome bzw. 1 Woche nach Auftreten des Ikterus sollten Kinder und Erwachsene mit akuter Hepatitis A vom Besuch einer Gemeinschaftseinrichtung ausgeschlossen werden. Eine Riegelungsimpfung ist je nach Situation zu erwägen. 


\section{Hepatitis B}

Mit Hepatitis-B-Virus (HBV) chronisch infizierte Kinder (Kap. \ „Hepatitis bei Kindern und Jugendlichen“) können in den Kindergarten aufgenommen werden, wenn sie kein ungewöhnlich aggressives Verhalten (Beißen, Kratzen) zeigen und keine besonderen Faktoren vorliegen, die das Übertragungsrisiko durch den Kontakt mit Blut erhöhen könnten, wie z. B. eine unkontrollierte Blutungsneigung. In Zweifelsfällen muss die Entscheidung über die Zulassung individuell auch unter Berücksichtigung der Viruslast erfolgen (Gesundheitsamt). Die Betreuungsperson sollte über den Trägerstatus des Kindes informiert sein, wobei die Vertraulichkeit dieser Information gegenüber allen, die sie nicht zur Wahrung der Gesundheit des betreffenden Kindes oder anderer benötigen, gewahrt bleiben muss. Sollte ein ungeimpftes Kind oder eine Betreuungsperson von einem chronisch-infizierten Kind gebissen werden oder anderweitig einem Infektionsrisiko ausgesetzt gewesen sein, muss umgehend die Notwendigkeit einer Postexpositionsprophylaxe überprüft werden. Da auch bislang undiagnostizierte HBV-Infizierte in den Kindergarten aufgenommen werden, müssen alle Betreuungspersonen bezüglich Hygienemaßnahmen zur Verhütung der Exposition mit Blut oder Körperflüssigkeiten geschult werden und sollten über einen Impfschutz verfügen. Die Hepatitis-B-Impfung der Säuglinge, Kinder und Jugendlichen gehört zu den empfohlenen Impfungen der STIKO (Kap. \,Impfungen und Reiseimpfungen bei Kindern und Jugendlichen").

\section{Hepatitis C}

Das Gleiche wie bei HBV (Abschn. 9.4, „Hepatitis B“) gilt auch für Hepatitis-C-Virus-Träger unter den Beschäftigten oder den Kindern einer Einrichtung. Eine Ausnahme stellen Kinder mit ungewöhnlich aggressivem Verhalten (Beißen, Kratzen) oder einer Blutungsneigung dar. In diesen (Zweifels-)Fällen muss die Entscheidung über die Zulassung zu einer Gemeinschaftseinrichtung ebenfalls individuell getroffen werden. Ein Ausschluss von Kontaktpersonen ist nicht erforderlich. Generell muss vermieden werden, dass Blut von HCV-Infizierten, z. B. bei Verletzungen von Haut oder Schleimhäuten, in die Blutbahn oder das Gewebe einer anderen Person gelangt.

\section{HIV}

Auch hier gilt das oben bei HBV und HCV Gesagte (Kap. $\checkmark$ „HIV-Infektion und AIDS bei Kindern und Jugendlichen"). Kein Infektionsrisiko stellen Körperkontakte im alltäglichen sozialen Miteinander, die gemeinsame Benutzung von Geschirr, Besteck und ähnliches sowie die gemeinsame Benutzung sanitärer Einrichtungen dar. HIV wird nicht über Speichel, Tränenflüssigkeit, Tröpfcheninfektion, durch Insektenstiche oder über Nahrungsmittel oder Trinkwasser übertragen, ebenso wenig durch Kontamination von intakter Haut mit virushaltiger Körperflüssigkeit. Auf der anderen Seite muss das infizierte Kind entsprechend seiner aktuellen Immunkompetenz (CD4-Status) selbst vor Infektionen geschützt werden. Dabei spielen nicht nur Vorsichtsmaßnahmen bei manifesten Infekten, sondern auch die korrekte Durchimpfung der anderen Kinder eine Rolle.

\section{Parvovirus B19}

Die Infektion mit Parvovirus B19 (Kap. \ „Parvovirus-B19Infektionen bei Kindern und Jugendlichen") verläuft bei ca. $20 \%$ der Infizierten asymptomatisch. Das Erythema infectiosum, die häufigste Manifestation, tritt hauptsächlich bei Kindern auf. Der Ausschluss infizierter Personen von Gemeinschaftseinrichtungen ist weitgehend wirkungslos, da das Virus bei Auftreten des Exanthems bereits kaum noch im respiratorischen Sekret nachweisbar ist. Die Wahrscheinlichkeit, dass während eines Ausbruchs mit Parvovirus B19 bei einer schwangeren Betreuungsperson eine Schädigung des Föten eintritt, liegt unter $1 \%$. Ein grundsätzlicher Ausschluss Schwangerer von der Arbeit im Kindergarten wegen des Risikos dieser Infektion ist auf Grund des sehr geringen Risikos in Anbetracht der gleichzeitigen ,natürlichen“ Exposition im privaten Umfeld umstritten und aus Sicht der Autoren nicht sinnvoll.

\section{Weiterführende Literatur}

American Academy of Pediatrics (2012) In: Pickering LK (Hrsg) Red book: 2012 report of the Committee on Infectious Diseases, 29. Aufl. American Academy of Pediatrics, Elk Grove Village

Arne S (Hrsg) (2018) Evidenz-basierte Empfehlungen zur Anwendung dauerhaft implantierter, zentralvenöser Zugänge in der pädiatrischen Onkologie, 5. Aufl. MHP, Wiesbaden (im Druck)

AWMV-Leitlinie Tuberkulose 048 - 016 Bundesamt für Verbraucherschutz und Lebensmittelsicherheit (2011) GERMAP 2010 Antibiotika-Resistenz und -Verbrauch

KRINKO (2012) Hygienemaßnahmen bei Infektionen oder Besiedlung mit multiresistenten gramnegativen Stäbchen im Zusammenhang mit der von EUCAST neu definierten Kategorie „I“ bei der AntibiotikaResistenzbestimmung: Konsequenzen für die Definition von MRGN. Epidemiol Bull 9:82

Dettenkofer M, Frank U, Just H-M, Lemmen S, Scherrer M (2018) Praktische Krankenhaushygiene und Umweltschutz, 4. Aufl. Springer, Berlin/Heidelberg/New York/Tokyo

Deutsche Gesellschaft für pädiatrische Infektiologie (2018) Handbuch: Infektionen bei Kindern und Jugendlichen, 7., erw. u. überarb. Aufl. Thieme, Stuttgart

Deutsche Gesellschaft für pädiatrische Infektiologie. https://dgpi.de/ umgang-mit-mrsa-nachweisen-bei-gesunden-kindern/. Zugegriffen im Juni 2018

Empfehlung der Kommission für Krankenhaushygiene und Infektionsprävention (KRINKO) beim Robert Koch-Institut (2015) Infektionsprävention im Rahmen der Pflege und Behandlung von Patienten mit übertragbaren Krankheiten. Bundesgesundheitsbl 58:1151-1170. https://doi.org/10.1007/s00103-015-2234-2

Ergänzung zur Empfehlung der KRINKO „Hygienemaßnahmen bei Infektionen oder Besiedlung mit multiresistenten gramnegativen Stäbchen“ (2012) im Zusammenhang mit der von EUCAST neu 
definierten Kategorie „I“ bei der Antibiotika-Resistenzbestimmung: Konsequenzen für die Definition von MRGN. Epidemiol Bull 9:82

Faust F, Göpel W, Hering E, Härtel C (2011) Sepsis bei Frühgeborenen mit einem sehr niedrigen Geburtsgewicht. Chemotherapie J 20:1-8

Feiterna-Sperling C et al (2017) S2k-Leitlinie zur Diagnostik, Prävention und Therapie der Tuberkulose im Kindes- und Jugendalter. Pneumologie 71:629-680

Fussen R, Lemmen S (2015) Prevention of transmission of multidrugresistant bacteria. Internist (Berl) 56(11):1246-1254

Grohskopf LA, Huskins WC, Sinkowitz-Cochran RL, Levine GL, Goldmann DA, Jarvis WR, Pediatric Prevention Network (2005) Use of antimicrobial agents in United States neonatal and pediatric intensive care patients. Pediatr Infect Dis J 24:755-772

Hygienemaßnahmen bei Infektionen oder Besiedlung mit multiresistenten gramnegativen Stäbchen (2012). Bundesgesundheitsbl 55(10): $1311-1354$

Kommission für Krankenhaushygiene und Infektionsprävention am RKI (2002) Prävention Gefäßkatheter-assoziierter Infektionen. Bundesgesundheitsbl Gesundheitsforsch Gesundheitsschutz 45:907-924

Kommission für Krankenhaushygiene und Infektionsprävention am RKI (2018) Prävention von Gefäßkatheterassoziierten Infektionen bei Früh- und Neugeborenen. Bundesgesundheitsbl 61:608-626. https://doi.org/10.1007/s00103-018-2718-y

Kommission für Krankenhaushygiene und Infektionsprävention beim Robert Koch-Institut (2007) Empfehlung zur Prävention nosokomialer Infektionen bei neonatologischen Intensivpflegepatienten mit einem Geburtsgewicht unter 1500 g. Gesundheitsbl-Gesundheitsforsch-Gesundheitsschutz 50:1265-1303. http://www.rki.de/DE/ Content/Infekt/Krankenhaushygiene/Kommission/kommission_node. html. Zugegriffen am 28.11.2013

Kommission für Krankenhaushygiene und Infektionsprävention beim Robert Koch-Institut (2011) Ergänzende Empfehlung zur „Prävention nosokomialer Infektionen bei neonatologischen Intensivpflegepatienten mit einem Geburtsgewicht unter 1500 g“ (2007). Epidemiol Bull 2:421

Kommission für Krankenhaushygiene und Infektionsprävention beim Robert Koch-Institut (2013) Praktische Umsetzung sowie krankenhaushygienische und infektionspräventive Konsequenzen des mikrobiellen Kolonisationssscreenings bei intensivmedizinisch behandelten Früh- und Neugeborenen. Epidemiologisches Bulletin Nr. 42; 21. Oktober 2013

Kommission für Krankenhaushygiene und Infektionsprävention beim Robert Koch-Institut (2016) Händehygiene in Einrichtungen des Gesundheitswesens - Empfehlung der Kommission für Krankenhaushygiene und Infektionsprävention (KRINKO) beim Robert Koch-Institut (RKI). Bundesgesundheitsbl 59:1189-1220. https:// doi.org/10.1007/s00103-016-2416-6

KRINKO-Empfehlung Anforderung an die Hygiene bei Punktionen und Injektionen (2011) Bundesgesundheitsbl 54:1135-1144

Leistner R, Piening B, Gastmeier P, Geffers C, Schwab F (2013) Nosocomial infections in very low birthweight infants in Germany: current data from the National Surveillance System NEO-KISS. Klin Padiatr 225(02):75-80. https://doi.org/10.1055/s-0033-1334886

Mayhall CG (2012) Epidemiology and prevention of nosocomial infections in pediatric patients. In: Hospital epidemiology and infection control, 4. Aufl. Williams \& Wilkins, Baltimore, S 783-913

Polin RA and the Committee on Fetus and Newborn (2012) Management of neonates with suspected or proven early-onset bacterial sepsis. American Academy of Pediatrics: www.pediatrics.org/cgi/ doi/10.1542/peds.2012-0541. Zugegriffen am 28.11.2013

Robert Koch-Institut (2013) Empfehlungen der Ständigen Impfkommission (STIKO). Epidemiol Bulletin 26. August 2013/Nr. 34

Saiman L (2003) Preventing infections in the neonatal intensive care unit. In: Wenzel RP (Hrsg) Prevention and control of nosocomial infections, Bd 4. Williams \& Wilkins, Baltimore, S 342-368

Schulze-Röbbecke R (2006) Isolierung infektiöser Patienten - auf die Übertragungswege kommt es an. Krankenhaushygiene up2date 1:97-114

Schulz-Stübner S (Hrsg) (2017) Spezielle Erreger und Infektionen. In: Repetitorium Krankenhaushygiene, hygienebeauftragter Arzt und ABS-beauftragter Arzt, 2. Aufl. Springer, Berlin, S 350-363

Siegel JD, Rhinehart E, Jackson M, Chiarello L, Healthcare Infection Control Practices Advisory Committee (HICPAC) (2007) Guideline for isolation precautions: preventing transmission of infectious agents in healthcare settings. www.cdc.gov

WHO Leitlinien zur Händehygiene im Gesundheitswesen 